\title{
UN ARRIAZ BRONCÍNEO DECORADO, DE ESPADA DE ÉPOCA OMEYA ANDALUSÍ, HALLADO EN EL OCCIDENTE DEL ALFOZ DE MADĪNAT QURṬUBA (CÓRDOBA)
}

\author{
POR \\ Rafael CARMONA Avila*
}

\section{RESUMEN - ABSTRACT}

Damos a conocer en este artículo un arriaz de espada hallado, de modo casual, en el yacimiento arqueológico de Los Algarbes (Écija, Sevilla) y que forma parte de los fondos del Museo Histórico "Juan Bernier" de La Carlota (Córdoba). El arriaz está fundido en bronce y presenta una decoración sencilla, en relieve, con un motivo central figurado (cabeza de rasgos antropomorfos que identificamos como perteneciente a un ŷinn o genio de la mitología mágica islámica) del que parten a ambos lados sendos motivos vegetales de palmetas. El arriaz es de brazos curvados hacia la hoja y de marcada influencia bizantina, si bien hemos de considerarlo como una producción cordobesa de época omeya, muy probablemente califal. La escasez de la cultura material asociada a espadas para este periodo hacen del arriaz de Los Algarbes un referente excepcional y obligado para conocer la panoplia militar andalusí altomedieval.

In this article we present a sword crossguard found casually in the archaeological settlement of Los Algarbes (Ecija, Sevilla), which is part of the funds of the Historical Museum "Juan Bernier" in La Carlota (Córdoba). The crossguard is made of bronze and has a simple decoration, in relief, with a central figurative element (one head with anthropomorphic features, which we identify as belonging to a $\hat{y}$ inn or a genie of magical islamic mythology) from which two palm-shaped motives are emerging on each side. This crossguard has curved arms towards the blade in a clear Byzantine style, although it must be considered as manufactured in Córdoba during the Omeya period, probably in the Caliphate time. The shortage of materials associated with swords of this period, turn the crossguard of los Algarves into an essential reference to comprehend the Andalusi military weapons of the early Middle Age.

\section{Palabras Clave - Keywords}

Córdoba. Califato. Espada. Arriaz. Omeya. Al-Andalus. Bizancio. Palmetas. Decoración figurada. Ŷinn. Magia.

Córdoba. Caliphate. Sword. Crossguard. Omeya. Al-Andalus. Byzancio. Palm-shaped. Figurative decoration. Yinn. Magic.

"Cuando Muhammad se convenció de que estaba cercado, se apoyó en su espada y se dio muerte..."

Anales palatinos del califa de Córdoba Al-Hakam II

\footnotetext{
* Arqueólogo Municipal, Director del Museo Histórico de Priego de Córdoba.
} 


\section{INTRODUCCIÓN}

Hace algunos años, Antonio Martínez Castro, del equipo directivo del Museo Histórico de La Carlota (Córdoba), nos comentó la existencia en los fondos de dicha institución de un bronce decorado -que se había catalogado como arriaz de un arma blanca medieval- hallado en un contexto andalusí rural, en concreto en el yacimiento arqueológico de Los Algarbes (t.m. Ecija, Sevilla), en el límite municipal con La Carlota (Córdoba). Una vez contrastada la información facilitada por el museo y visualizada la pieza, se nos ofreció la posibilidad de su estudio, por lo que las líneas que siguen son consecuencia de la aceptación por mi parte del amable ofrecimiento. Queda de manifiesto, pues, nuestro reconocimento hacia Antonio Martínez, que nos ha facilitado cuanta información le hemos demandado sobre las circunstancias y contexto del hallazgo, además de habernos acompañado durante nuestra visita al yacimiento de Los Algarbes.

\section{LOCALIZACIÓN E INTERPRETACIÓN DEL YACIMIENTO}

El cerro de Los Algarbes (Écija) se localiza entre la N-IV (A-4) y la carretera comarcal A-386 (C-3312), en el extremo NE del término municipal ecijano, de cuya capital dista unos $14 \mathrm{~km}$, y a unos $6,5 \mathrm{~km}$ al SW de la localidad cordobesa de La Carlota. Está formado por una loma de suaves pendientes que alcanza su cota máxima en el vértice geodésico Algarbes con $271,20 \mathrm{msnm}$. El desnivel entre este cerro y su entorno se sitúa entre los 33 y $44 \mathrm{~m}$, por lo que se constituye en un hito geográfico poco destacado en el paisaje, de cómodo acceso y dotado de una óptima habitabilidad. Las coordenadas puntuales del yacimiento son las siguientes: UTM 30S 0.328.297 4.164.429, 258,5 msnm, Datum ED 1950; hoja F96532 de la planera digital de Andalucía del ICA, E: 1:10.000. [Lám. I].

Según datos aportados por el Museo Histórico de La Carlota, el límite norte de la zona arqueológica está representado por el tránsito desde las margas gris azuladas del Mioceno superior, sobre las que se asienta la totalidad del yacimiento, hacia tierras de aluvión o raña pliocuaternaria, de mucha peor calidad agrícola por su abundancia en limos, arenas y cantos rodados [MGE 1:50.000, Écija 965 (15-39)]. La ausencia de restos arqueológicos en superficie es total al entrar en este último dominio arqueológico.

El yacimiento de Los Algarbes (Écija) se encuentra prácticamente inédito, a excepción de alguna somera referencia que ya apunta la entidad del mismo en base a la calidad de los hallazgos casuales asociados y que refiere la existencia de "parte de una espada con decoración antropomorfa y vegetal" en bronce, objeto de nuestro estudio (MARTíNEZ, 2002: 110-111).

Los Algarbes (Écija), y su prolongación homónima en el término de La Carlota (Córdoba), se sitúan en el occidente del antiguo alfoz de la medina de Qurtuba, tal como lo evidencia el topónimo, derivado del árabe al-garb, con ese significado, en oposición a al-šarq u oriente (WALSH, 1967, en MARTÍNEZ, 2003). Su posición geoestratégica es excelente ya que la antigua Vía Augusta discurre por las inmediaciones del yacimiento, a su poniente, según el itinerario reconstruido propuesto (MARTÍNEZ CASTRO, 2005). También cerca del yacimiento, al norte, se ha señalado la ubicación de la mansio Ad Aras, nombre que se ha relacionado con los mojones territoriales que debieron de existir en el límite entre la Corduba y la Astigi (Écija) romanas (MELCHOR, 1995: 95 y 96), y que discurren en este punto, de modo aproximado, por los mismos lugares que los de la posterior capital del califato. Se justifica así plenamente el topónimo de Los Algarbes, que quedan, respectivamente, a unos 39 y $14 \mathrm{~km}$ de distancia de ambas ciudades. Este camino se mantuvo durante la Edad Media andalusí como uno de los dos itinerarios terrestres posibles entre Qurṭuba e Istiŷŷa (Écija), y así aparece recogido por Al-Idrīsī en el siglo XII (AL-IDRĪSĪ, 1989: 81). 

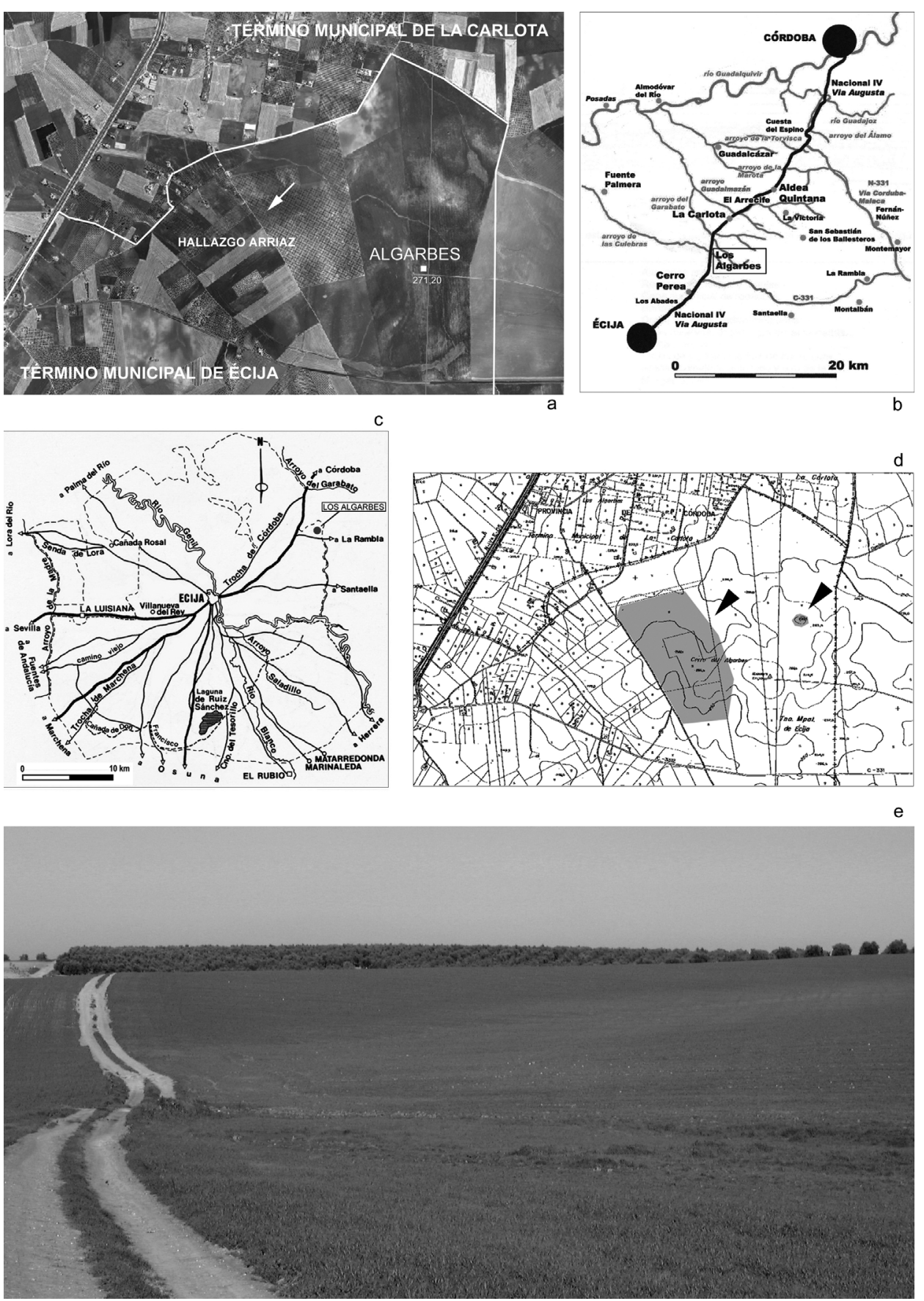

LÁM. I: a) Localización del hallazgo sobre fotografía aérea (Ortofotografía digital de Andalucía. Vuelo fotogramétrico a escala 1: 20.000, año 2001-1002), b) Situación de Los Algarbes, en las inmediaciones de la antigua Vía Augusta, entre Écija y Córdoba (MARTÍNEZ CASTRO, 2005: 66), c) Término municipal de Écija (DURÁN y PADILLA, 1990: 161) y localización de Los Algarbes en el sector Noreste, d) Sectores, en trama de grises, del yacimiento arqueológico de Los Algarbes (sobre cartografía 1:10000 del ICA), e) Panorámica general del yacimiento, en el olivar del horizonte, visto desde el Sureste. Todos los mapas y la fotografía aérea están orientados al Norte. 
Los datos expuestos en este artículo nos permiten interpretar el yacimiento arqueológico de Los Algarbes como un asentamiento rural andalusí de entidad, que tendríamos que identificar como una alquería o una almunia que, probablemente, nace y se desarrolla en época omeya, bajo la influencia de la proximidad del camino mencionado que unía Córdoba con Écija. Este lugar, que llegó a tener determinadas instalaciones industriales (v. infra), parece que no pudo sobrevivir a la crisis de la fitna, salvo mediante una ocupación ocasional y muy limitada. La abrumadora cultura material asociada perteneciente a época omeya, tal como veremos más adelante, así parece indicarlo. Su distancia a Qurtuba (una jornada) e Istiŷŷa -Écija- (media jornada) lo convierten en un punto geoestratégico que benefició, sin duda alguna, a sus habitantes.

\section{DESCRIPCIÓN DEL ARRIAZ}

Definición: Arriaz decorado de espada, fundido en bronce, y brazos curvados con extremos orientados hacia la hoja [Lám. II y III].

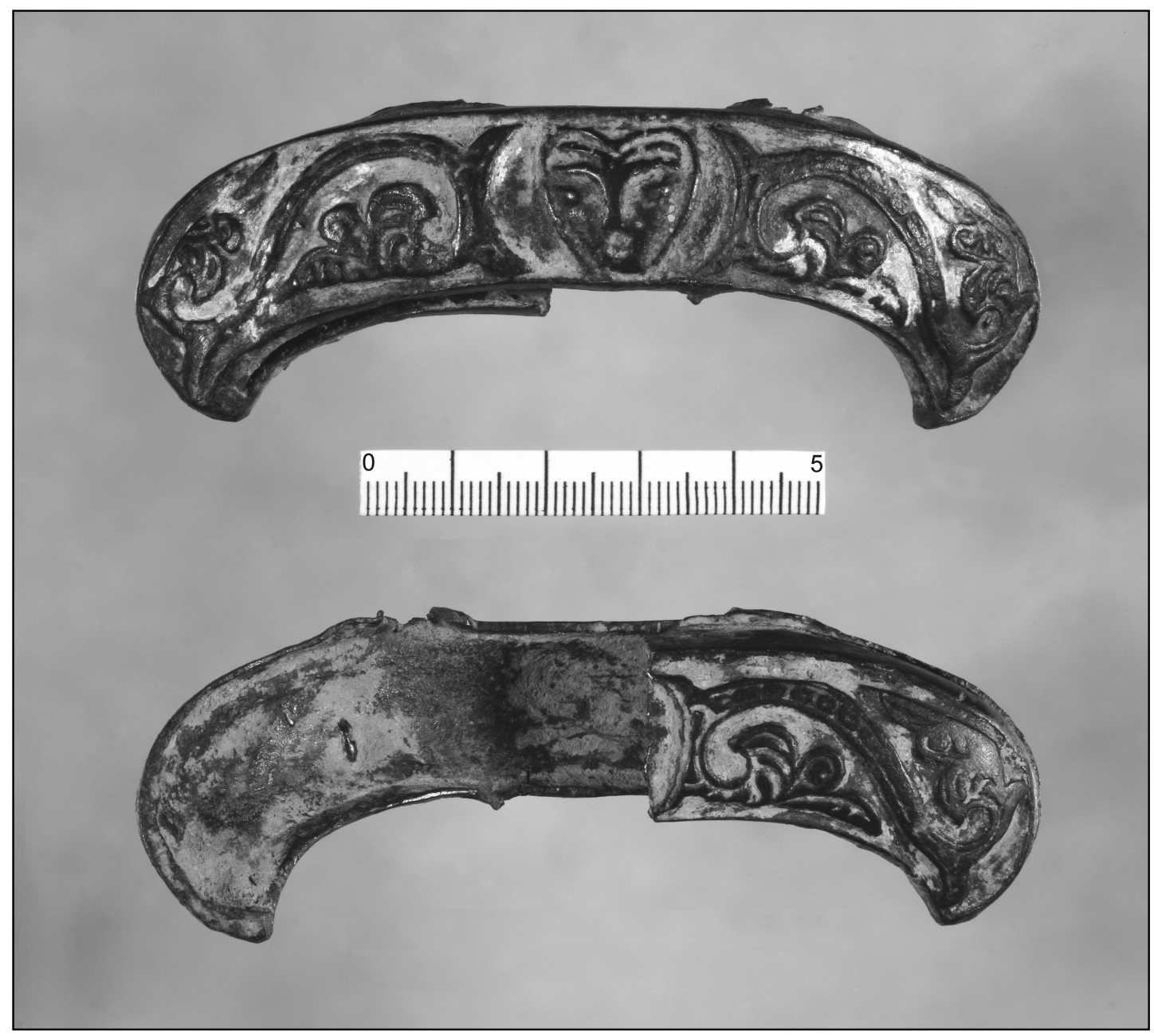

LÁM. II: Fotografía del arriaz de Los Algarbes. 


\section{Dimensiones:}

Longitud: 101,4 mm (por deformación, sólo alcanza los 94,4 mm).

Ancho: $18,6 \mathrm{~mm}$.

Grosor arriaz: $17 \mathrm{~mm}$.

Grosor lámina de bronce: de $1,5 \mathrm{~mm}$ a $3 \mathrm{~mm}$ (irregular).

Peso: $60,750 \mathrm{~g}$.

Tecnología: Fundido en dos piezas simétricas de bronce, a molde, soldadas con posterioridad.

Conservación: Uno de los lados se encuentra parcialmente perdido, por fractura, que denominaremos lado B para diferenciarlo del contrario, que se ha mantenido completo -lado A-. El bronce se encuentra bien conservado, con pátina noble de malaquita, color verde oscuro, con algunas adherencias terrosas y manchas de carbonato cálcico blanquecinas. Sobre el metal se dispone una capa de óxido de cobre (rojo) que es observable sólo en aquellos puntos en los que se ha desprendido la pátina de malaquita. La pieza presenta deformaciones.

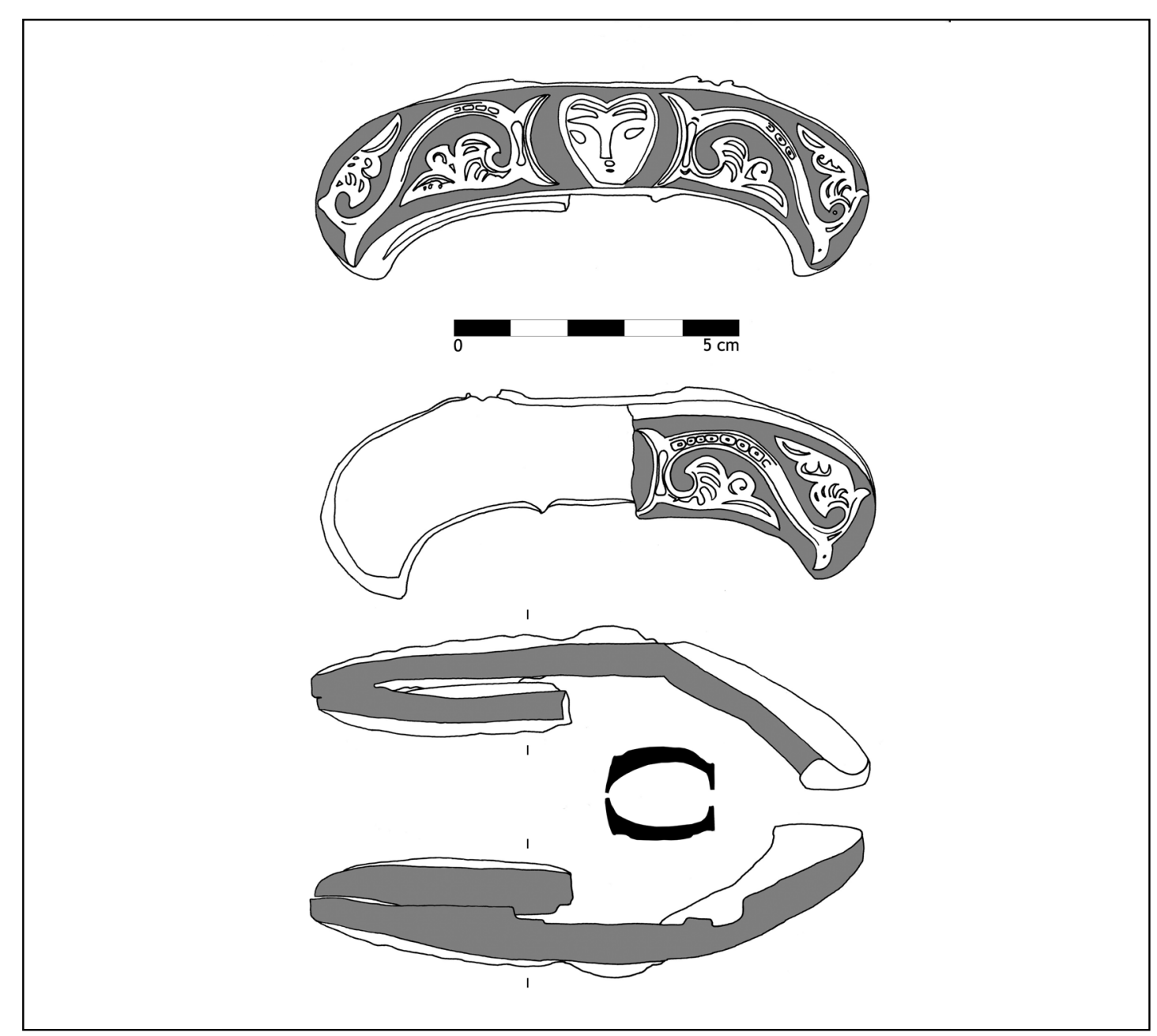

LÁM. III: Dibujo del arriaz de Los Algarbes. 
Decoración: A molde e igual en ambos lados, según deducimos de lo conservado en sendas partes (lados A y B), que se corresponden, por lo tanto, con un mismo molde, al coincidir la ejecución de los diferentes motivos. Las diferencias apreciables corresponden a un desigual estado de conservación y a irregularidades propias de la fundición.

\section{Lado A:}

En el centro, una cabeza antropomorfa muy estilizada, al frente, de forma acorazonada, sin orejas señaladas, de la que parten a ambos lados, dispuestas simétricamente, unas palmetas vegetales.

La cabeza presenta ojos almendrados, saltones, y un entrecejo unido a la nariz en disposición que recuerda a la letra Y. Sobre el entrecejo se dibujan dos líneas más finas, que convergen en el punto de unión de las cejas con la parte superior de la nariz. La boca se indica con un par de pequeñas punciones, una sobre otra, si bien una de ellas pudiera querer representar los orificios de la nariz.

Las palmetas se disponen en sendos extremos de un tallo con forma sinusoide, a modo de letra $S$ tumbada, partiendo de una horquilla que enmarca la cabeza antropomorfa en cada uno de sus lados. Este tallo muestra una decoración de una serie de anillos aplanados consecutivos, enmarcados entre dos líneas, de desigual ejecución y conservación, con un punto marcado central. Las hojas, cada una de ellas, presentan tres lóbulos abiertos en abanico, los dos de los extremos apuntados y el central redondeado. Las hojas tienen decoración interior foliácea, dando un aspecto general de hojas dentro de hojas.

\section{Lado B:}

Se repite el esquema anterior, pero no se conserva el motivo vegetal de la izquierda ni la cabeza, aunque sí el vegetal derecho.

La decoración en ambos lados se presenta en relieve, que sobresale del fondo plano entre $1 \mathrm{~mm}$ (motivos vegetales) y 3,6 mm (cabeza). La cabeza tiene unas dimensiones de 15,4 $\mathrm{mm}$ (alto) por 16,1 mm (ancho). El motivo vegetal izquierdo del lado A tiene un ancho de 41,5 $\mathrm{mm}$ por un alto medio de $16 \mathrm{~mm}$.

Evidencias sobre las características de la hoja de espada: Aunque no se ha conservado nada de la hoja de espada correspondiente ni del resto de la empuñadura, el arriaz aporta algunos datos indirectos relacionados con estos elementos. No es éste un dato baladí ni ajeno a valoraciones simbólicas, no en vano sabemos que en el islam lo trascendente no está en las características de la empuñadura de una espada, sino en las de su hoja, así como en una persona no son sus adornos externos sino los valores del individuo como tal (MARTÍNEZ ENAMORADO, 2005: 300).

En la parte superior se aprecia parte del entalle destinado a albergar la espiga, de la que poco podemos decir, salvo que era de sección rectangular y unas dimensiones aproximadas en torno a $21,5 \mathrm{~mm} \times 3 \mathrm{~mm}$. A ambos lados, se conservan dos muescas, una de ellas fracturada, de una longitud de unos $3,4 \mathrm{~mm}$, que podríamos relacionar con el sistema de cubrición de la espiga, o bien con unos hipotéticos pasadores que sujetaran alguna pieza metálica que formara parte de la empuñadura, tal como es característico, por ejemplo, en algunas manzanas de espadas vikingas (PEIRCE, 2002), o se insinúa en determinadas espadas islámicas desde los siglos altomedievales (NICOLLE, 2002: 165, fig. 38, y 179, fig. 114). De todas formas, el estado de conservación del arriaz en este punto no nos permite ser concluyentes.

En la parte inferior se dispone parte de la ranura destinada al arranque de la hoja, con un ancho de unos 2,8 $\mathrm{mm}$ y una longitud total reconstruida de unos $73 \mathrm{~mm}$ (conservados: 29,6 mm). Este dato es importante pues nos aporta el ancho máximo que pudo tener la hoja $-73 \mathrm{~mm}-$, si 
bien ésta no tuvo que disponerse necesariamente aprovechando la totalidad del espacio, tal como concluimos, por ejemplo, tras el estudio de esta característica en varias decenas de espadas vikingas -de manufactura vikinga o franca- expuestas en el Historisk Museum de Oslo (de visu), en las que la hoja de la espada puede dejar parte de la ranura sin ocupar. Sobre esta característica volveremos más adelante.

Por último, el arriaz conserva huellas de una perforación provocada por un objeto afilado, a modo de punzón, con orificio de entrada y salida, que se usó para arrancar el arriaz de la espada a la que pertenecía, operación ésta que ha sido la causante de la deformación del mismo y, quizás también, de su rotura. Esta perforación se realiza en la línea de unión entre ambas mitades del arriaz, punto especialmente débil y que permitiría la separación de ambas ejerciendo una fuerza determinada.

\section{CRONOLOGÍA}

Para datar el arriaz de Los Algarbes podemos aprovechar la doble vertiente ofrecida tanto por el diagnóstico formal de la pieza y de los motivos que la decoran -aunque con las cautelas propias que nos hacen saber que las dataciones estilísticas no siempre han coincidido con las radiocarbónicas (CABRERA, 2005: 14)- como por el contexto arqueológico del que procede. En ambos casos, las conclusiones son similares, aunque la falta de un contexto arqueológico inmediato, tal como se habría producido en el caso de haberse recuperado la pieza en el transcurso de una excavación arqueológica científica, nos hace mantener las cautelas oportunas para este tipo de hallazgos.

\section{El objeto: consideraciones formales}

Los arriaces curvos se vienen considerando como de tipo oriental (NICOLLE, 2002: 178 y 180), aunque esta influencia puede deberse tanto a un origen directo como a la asimilación de un estilo o moda. Con una curvatura más o menos pronunciada, están testimoniados tanto en el registro arqueológico del ámbito mediterráneo, parco de todos modos, como en las fuentes iconográficas, caso de los beatos altomedievales cuando en éstos se representa el armamento islámico. Curvo, y paradigmático, es el arriaz de la espada representada en la conocida como arqueta "de los dos emperadores", muestra de la eboraria bizantina del siglo X d.C. conservada en la catedral de Troyes [Lám. VIIId] (GALÁN, 2005: I, 69; HEATH, 2002: 7), que tiene paralelos más antiguos en, por ejemplo, una escultura del palacio omeya de Khirbat al-Mafjar, del siglo VIII d.C. (ALEXANDER, 2001: 194).

Pero tampoco son desconocidos en la Europa cristiana (FAGNEN, 2005: 21), aunque en esta ocasión se han entendido como ejemplo de influencias orientales, más o menos directas. Sólo será en un momento tardío, en torno al siglo XIII, cuando este tipo de arriaz se asocie a espadas cristianas occidentales, en la península Ibérica, pero con una variación formal -son más largos y estrechos- que permiten su diferenciación. Para Soler (SOLER, 1993: 15, 16 y 304-306), la representación iconográfica española más antigua de un arriaz curvo es de finales del siglo X, cuando aparece en el Codex Aemilianense, y se mantendrá durante toda la Edad Media. Más recientemente, en Córdoba ha sido hallado un fragmento de ataifor decorado con la técnica de verde y manganeso, de cronología califal, que representa a un personaje masculino barbado (ijinete?) portando una espada de hoja corta con un arriaz de este tipo [Lám. IV] (CAMACHO, HARO, LARA y PÉREZ, 2004: 224), y que recuerda a decoraciones similares de las cerámicas persas islámicas de los siglos IX y X [Lám. VIIIc y VIIIf].

Los paralelos más exactos que conocemos para el arriaz de Los Algarbes -dejando a un lado su recurso decorativo y en función exclusiva de sus proporciones y diseño- se encuen- 


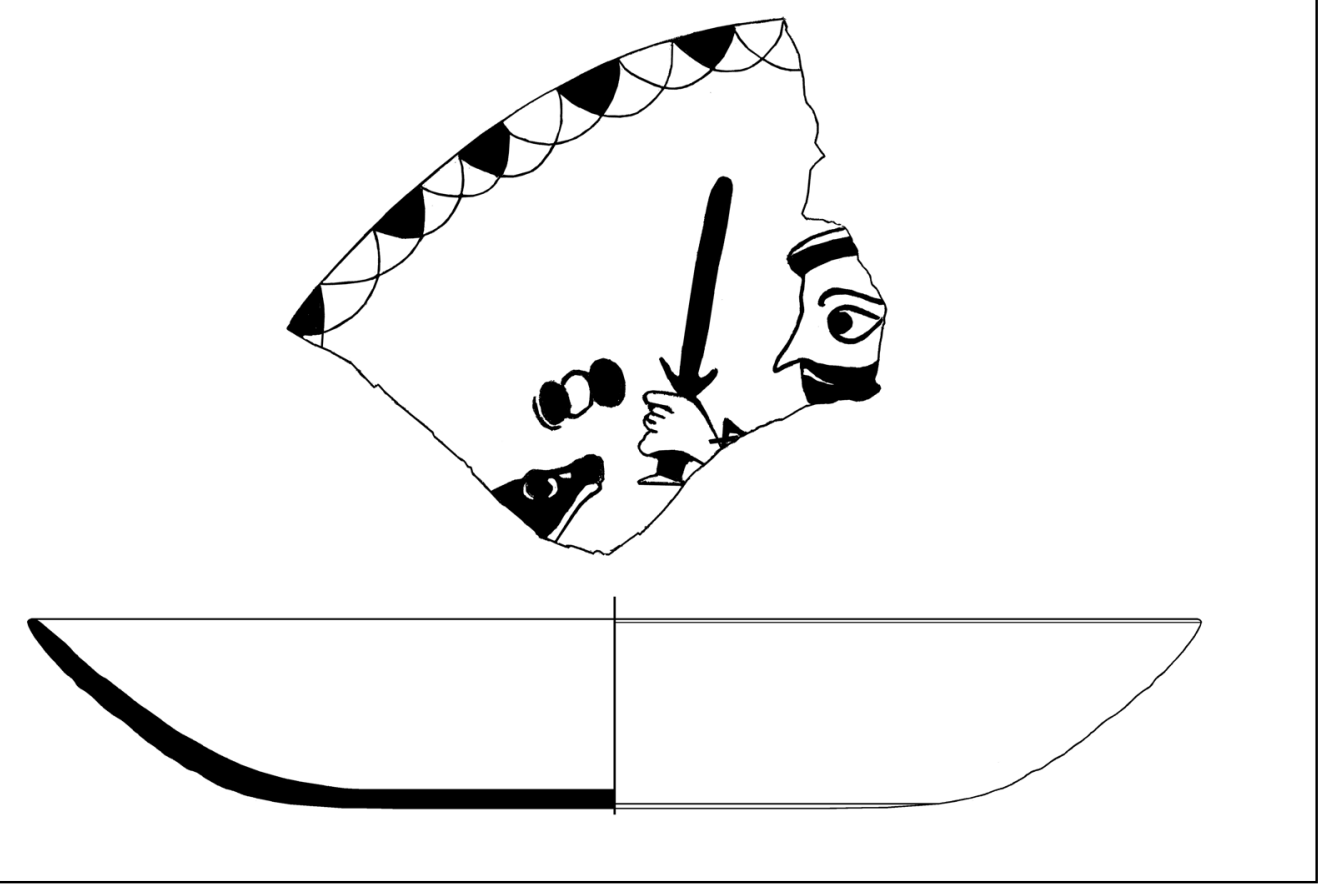

LÁM. IV: Ataifor califal, con decoración figurada en verde y manganeso, procedente de las excavaciones de los arrabales occidentales de Qurțuba (CAMACHO, HARO, LARA y PÉREZ, 2004: 224). Dibujo de J.M. Lara.

tran en las fuentes iconográficas medievales, de los beatos principalmente, $\mathrm{y}$, también, en el registro arqueológico, con el hallazgo de las espadas de Martin's Cave de Gibraltar (NICOLLE, 2002).

En el primer caso, en el Beato del Burgo de Osma, [p.ej., ff. 85v y 145v], fechado en 1086, y en el Beato Corsini [p.ej., f. 126], este tipo de arriaz es uno de los que se representa, asociado a espadas de hoja ancha y canal central [Lám. Va y Vb]. En esta iconografía el ancho de la hoja ocupa toda la ranura del arriaz, que no deja espacio alguno entre los extremos curvados de éste y el filo de la hoja. Por el contrario, en una miniatura del códice Semblanza de Reyes (siglo XI), que representa a Țāriq junto a Rodrigo, vuelve a reproducirse esta clase de arriaz, si bien ahora dejando un espacio entre la hoja, más estrecha, y los extremos de los gavilanes. Para un tipo similar pero no idéntico, por ejemplo en el Codex Calixtinum, de hacia 1160-1170, un arriaz de extremos más redondeados se asocia igualmente a una espada ancha, sin canal central, y dejando también un hueco entre éstos y el filo de la hoja (SOLER, 1993: 213); este autor denomina a esta variante como Tipo $\mathrm{C}$ o arriaces "curvos o rectos con volutas en los extremos" (SOLER, 1993: 12 y 302), mientras que no recoge la tipología del arriaz de Los Algarbes en su estudio que, recordemos, se circunscribe a los siglos XII al XIV y tanto para territorio andalusí como para el reino cristiano catellano-leonés.

El registro arqueológico sí aporta un paralelo formal bastante exacto, peninsular, con una de las dos espadas encontradas en Martin`s Cave, Gibraltar, datada en el siglo XII d.C., y considerada como de origen andalusí o norteafricano [Lám. Vd] (NICOLLE, 2002). En este caso el arriaz es adscrito al tipo 9 de E. Oakeshott (NICOLLE, 2002: 151) y presenta decoración punteada que se extiende por toda la empuñadura. La hoja asociada, por contra de lo aportado en la iconografía de los beatos, es larga y estrecha, dejando un espacio entre el filo de la misma y los extremos curvados del arriaz. 
En Europa, la iconografía medieval aporta algún ejemplo de este tipo de arriaz, como en una de las miniaturas (lat. 1118, fol. 111) del Tropaire de Saint-Martial de Limoges (siglo XI), conservado en la Biblioteca Nacional de Francia [Lám. Vc]. Ahora la hoja es larga y estrecha y no deja espacio entre el filo de la misma y los extremos curvos del arriaz.

Como conclusión a este apartado, sólo podemos contrastar la existencia formal del tipo de arriaz de Los Algarves en los siglos XI y XII, como mínimo, aunque sin conocer sus prolongaciones por ambos extremos, ante la falta de paralelos conocidos. Tendremos que recurrir, entonces, al contexto arqueológico integrado por la cultura material asociada al lugar del hallazgo y a su estudio iconográfico. De igual modo, el tipo de arriaz lo vemos asociado tanto a espadas largas y estrechas, sin canal central, como a espadas cortas, de hoja ancha y con canal central. Es evidente, entonces, su polivalencia, dado que no podemos asociar el tipo de arriaz con un único y determinado tipo de hoja, si bien hemos de advertir que las fuentes utilizadas no son contemporáneas y que la asociación de arriaz a las hojas cortas y anchas son las más antiguas, como corresponde a este tipo de hoja.

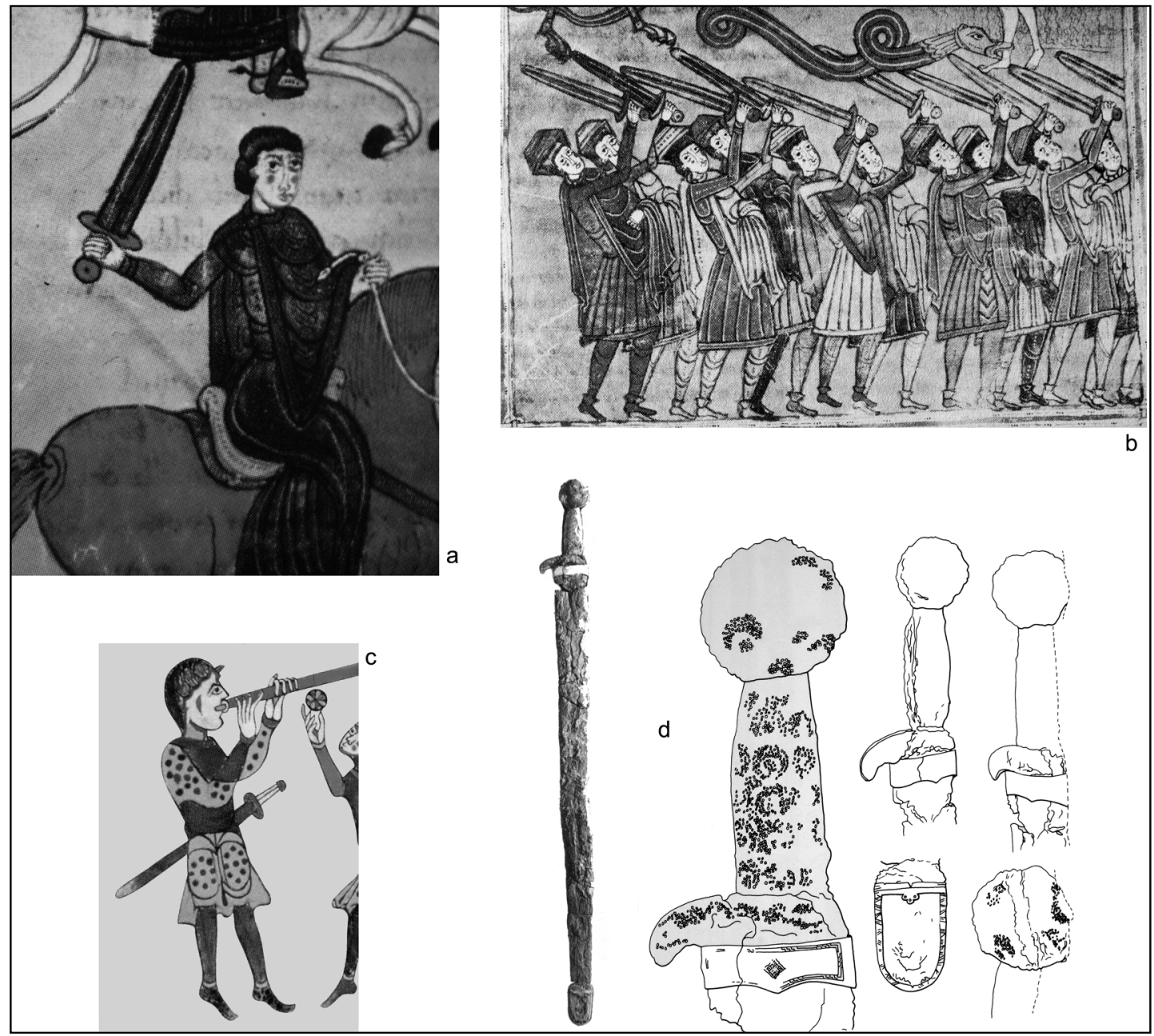

LÁM. V: a) y b) Representación de arriaces curvos, del tipo de Los Albarbes, en el Beato del Burgo de Osma, c) Miniatura del Tropaire de Saint-Martial, d) Espada encontrada en la Martin's Cave de Gibraltar (NICOLLE, 2002: 153-154). 


\section{El contexto arqueológico: la cultura material procedente del yacimiento}

Los restos materiales andalusíes que aparecen repartidos en superficie por el Cerro de los Algarbes se dispersan en torno a dos sectores claramente diferenciados [Lám. Id]. Por un lado, un polígono de unos $548.000 \mathrm{~m}^{2}$-ejes máximos de $1.190 \mathrm{~m}$ x $596 \mathrm{~m}$-, que constituye el núcleo principal del yacimiento, y donde fue hallado el arriaz; y un segundo, mucho más reducido, de $12.000 \mathrm{~m}^{2}$-ejes máximos de $150 \mathrm{~m} \mathrm{x} 125 \mathrm{~m}-$, y que se ubica a unos $500 \mathrm{~m}$ al este del primero. La presencia de tejas con fallos de cocción en el segundo punto nos podría indicar la presencia en éste de una instalación alfarera, lo que justificaría su ubicación apartada del núcleo principal del yacimiento, al tratarse de una actividad industrial molesta para la población.

La cultura material a la que hemos tenido acceso procede fundamentalmente del núcleo principal del yacimiento -cerámicas, piedra trabajada, metales y numismática-, aunque también contamos con un pequeño lote numismático de gran interés hallado en el segundo. Todos los objetos estudiados se encuentran depositados en el Museo Histórico de La Carlota [Lám. VI]. Veamos, a continuación, algunos de ellos.

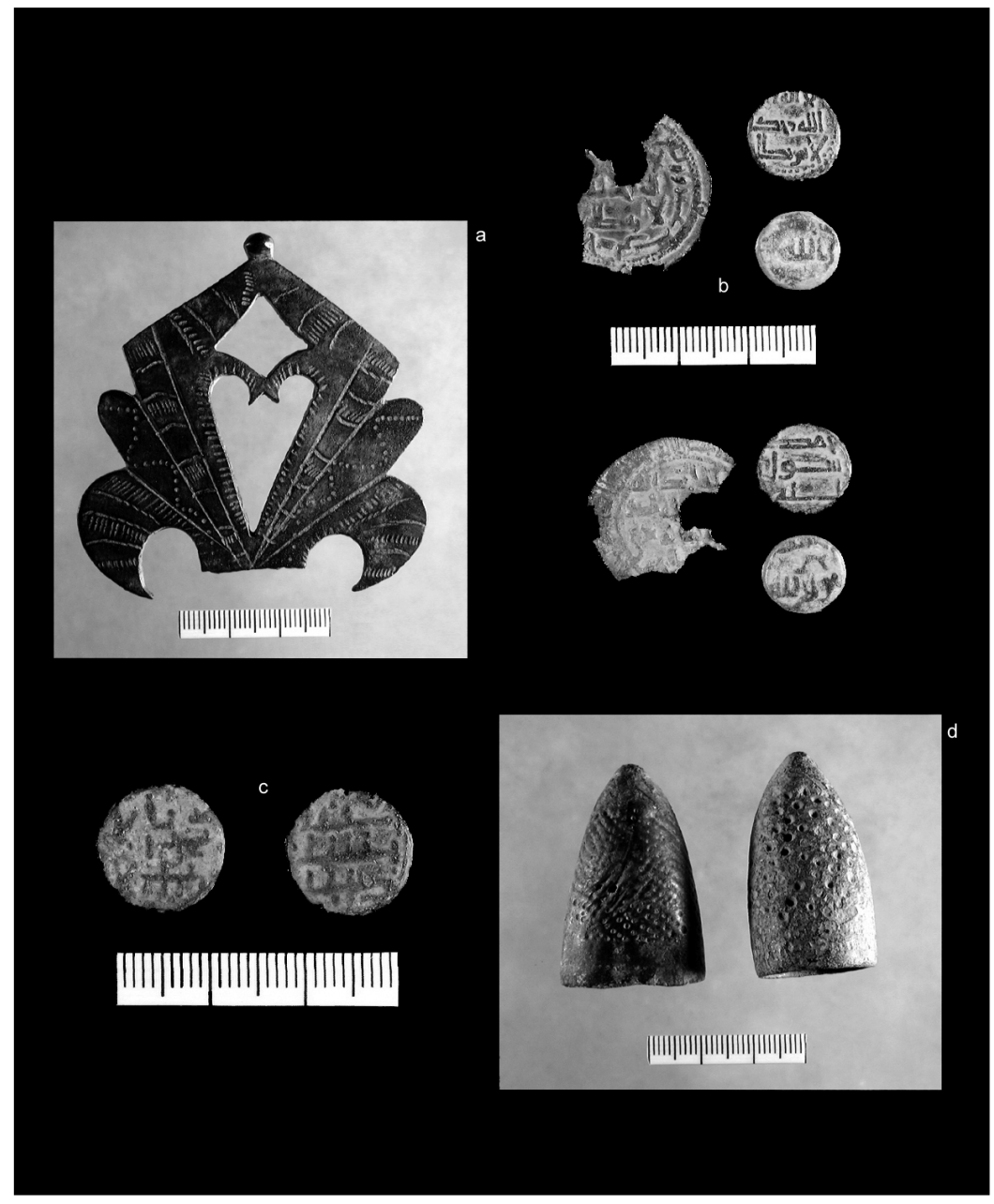

LÁM. VI: Cultura material procedente del yacimiento arqueológico de Los Algarbes, datable en los siglos IX-X d.C., y conservada en el Museo Histórico de La Carlota (Córdoba), a) Remate decorativo de asa de candil, b) Fragmento de dirham y feluses, c) Felus, d) Dedales de talabartero. 


\section{Cerámica}

En el museo se conservan unos 150 fragmentos cerámicos procedentes de Los Algarbes, la mayoría de pequeño tamaño -entre 2 y $6 \mathrm{~cm}$ de longitud máxima-. Aunque hay algún testimonio hispanorromano (tegulae y sigillata) o contemporáneo, la inmensa mayoría pertenecen a cerámicas andalusíes características de época omeya, con paralelos en los siglos IX y/o X y principios del XI d.C. (RETUERCE, 1998; VALLEJO y TRIANO, 1999; FUERTES, 2002). Las formas reconocidas, con los rasgos más representativos, son las siguientes:

- Ataifor. Perfiles clásicos, generalmente sin anillo de solero o poco desarrollado, vidriados melados o decorados con la técnica de verde y manganeso (un solo fragmento, sin engalba), o líneas de manganeso con cubierta melada. Un fragmento presenta decoración pseudoepigráfica.

- Jarra/o. Fragmentos decorados con líneas en blanco sobre engobe negro, o bien líneas en rojo o negro, sin engobe.

- Jarrita/o. Engobe rojo.

. Redoma/limeta. Base plano convexa. Vidriado melado, interior y exterior. Un fragmento decorado con verde manganeso.

- Olla. Base plana, sin vidriar.

- Tinaja. Con asas de orejas.

- Atípicos. Con vidriado melado al interior y sin vidriar al exterior.

\section{$\underline{\text { Piedra trabajada }}$}

Hallado en el yacimiento, se conserva en el museo un cimacio de piedra caliza blanca, de 29,6 cm x 18,5 cm (imcompl.) x 9,7 cm, reutilizado como quicialera, por lo que cuenta con las correspondientes abrasiones circulares. Corresponde a un tipo califal que, por sus dimensiones, debe de corresponderse con la arquitectura doméstica, quizás perteneciente a un doble arco de herradura vinculado a los accesos de una estancia privada.

\section{$\underline{\text { Metal }}$}

Remate decorativo de asa de candil (bronce, $72 \mathrm{~mm}$ x $69 \mathrm{~mm}$ x 2,5 mm) [Lám. VIa]. Se trata de una placa calada con motivos incisos perteneciente a un tipo de candil bien conocido y con una adscripción al siglo $\mathrm{X}$ califal, del que se considera un auténtico arquetipo, que tiene su mejor representación en un ejemplar completo conservado en el Instituto de Valencia de Don Juan de Madrid (CATÁLOGO, 2000: 117).

Dos dedales (bronce, [1]: $41 \mathrm{~mm}$ x 26,3 mm -deformado- x 2,5 mm. [2]: 40,9 $\mathrm{mm}$ x 21,8 $\mathrm{mm} \times 2,6 \mathrm{~mm}$ ) [Lám. VId]. Este tipo de dedales, apuntados y con punciones, se vienen publicando como dedales de talabartero o para el trabajo de las fibras vegetales, si bien otras interpretaciones más novedosas los identifican como dediles para percusión (de visu, en el Museo Arqueológico de Lorca). En todo caso, la cronología propuesta mayoritaria se sitúa en los siglos X y XI d.C. (CÓRDOBA y HERNÁNDEZ, 1994: 920).

\section{Numismática}

Sector 1 del yacimiento:

Felus de cospel grueso. Peso: 3,980 g; diámetro: 13,8 mm; grosor: 4 mm. orientación IIA: 12. Ceca: Al-Andalus (?) [Lám. VIc]. Emirato andalusí. En estudio, en todo caso anterior a la acuñación de feluses de cospel fino. 
Fragmento de quirate. Se trata de un minúsculo fragmento de moneda de plata de $10,8 \mathrm{~mm}$ x $5 \mathrm{~mm} \times 0,8 \mathrm{~mm}$ y $0,190 \mathrm{~g}$ de peso que creemos identificar con un quirate almorávide, en el que en la IIA parece leerse "hijo de Tasfin", lo que nos situaría en el año 537-540 H (1143-1145 d. C.) (MEDINA, 1992).

Además de estas dos monedas, tenemos noticias de la existencia de algunos feluses emirales más de cospel grueso y uno, al menos, de cospel fino, a ninguno de los cuales hemos tenido acceso.

Sector 2 del yacimiento [Lám. VIb]:

. Dirham incompleto. Ceca: Al-Andalus. Año: 210 H (825-826 d. C.). Peso (incompleto): 1,080 g; diámetro: 24,8 mm; grosor: $0,8 \mathrm{~mm}$; orientación IIA: 9. IA y IIA: leyendas usuales (MEDINA, 1992: 94ss).

- Felus de cospel grueso. Peso: 4,570 g; diámetro: 13,6; grosor: 4 mm, orientación IIA: 11. IA: Profesión de fe. IIA: Misión profética de Mahoma. Anterior al 206 H (821822 d. C.) (FROCHOSO, 2001).

- Felus de cospel grueso. Peso: 2,740 g; diámetro: 12,1 mm; grosor: 3,5 mm. orientación IIA: 6. IA: Profesión de fe (acuñación imperfecta). IIA: Misión profética de Mahoma. Anterior al 206 H (821-822 d. C.) (FROCHOSO, 2001).

\section{ESPADAS ANDALUSÍES DE ÉPOCA OMEYA: UN REGISTRO ARQUEOLÓGICO EXIGUO}

Hemos visto que la cultura material asociada al yacimiento arqueológico del que procede el arriaz nos remite mayoritariamente a época omeya andalusí. Si nos limitamos a estos momentos (siglo VIII- princ. siglo XI d.C.), el número de espadas conocidas en Al-Andalus es muy escaso. Tanto que sólo podemos aportar tres ejemplares conocidos por la bibliografía, los tres incompletos ${ }^{1}$. Además, el arriaz falta en uno de ellos, y en los dos que lo conservan son de hierro, sin resto alguno conservado de decoración. Ello hace imposible una comparación con el ejemplar de Los Algarbes, que se constituye de este modo, por sus características, en un unicum dentro de la arqueología andalusí. Las espadas que conocemos son las siguientes:

Espada de Liétor (Albacete) [Lám. VIIa]. Esta espada corresponde al extraordinario conjunto procedente de la ocultación realizada, entre finales del siglo X y la primera mitad del siglo XI d.C., en la Cueva de los Infiernos, en Liétor (NAVARRO y ROBLES, 1996: 91ss, lám. CXss). Los objetos recuperados son muy variados (utillaje agrícola y de diversos oficios y actividades artesanas, mobiliario y objetos domésticos, etc.) destacando, en lo que nos interesa, los elementos de armamento y atalaje militares (espada, lanza, escudo, bocado de caballo, jaeces, espuelas, trabas...). En concreto, la espada está representada por una hoja de hierro con su espiga, pero sin arriaz ni empuñadura conservadas. Es una hoja recta de doble filo, apuntada y con canal central. Su longitud es de $365 \mathrm{~mm}$, con un ancho de $67 \mathrm{~mm}$. La espiga tiene unas dimensiones de 145 X 27 X $5 \mathrm{~mm}$, lo que hace que el total de la espada alcance los $510 \mathrm{~mm}$ de longitud. Su peso es de 373 gramos. Dado el resto de objetos asociados, todo parece indicar que esta espada fue utilizada, a pesar de su escasa longitud, por un jinete. Detallamos sus proporciones porque esta hoja tiene unas dimensiones perfectamente compatibles,

${ }^{1}$ En 1979 se incluía en un trabajo sobre marfiles cordobeses (MONTOYA, 1979: 69, lám. 39) una placa de marfil de una empuñadura de espada que se conserva en el Museo Británico, y que era fechada en torno a 1025. Sin embargo, la bibliografía actualizada no deja lugar a dudas de que se trata de una producción otomana, de talleres egipcios, y una data que habría que situar entre los siglos XV y XVII (GALÁN, 2005, II: 452-453). 
en su latitud, con el arriaz de Los Algarbes, del que ya hemos señalado que pertenecía a una espada que debería tener, como máximo, un ancho de hoja de $73 \mathrm{~mm}$.

Espada de procedencia desconocida, quizás de algún lugar de la provincia de Córdoba [Lám. VIIc] (CANTO, 2001). Asociada a una ocultación monetaria realizada en torno al año 880 d.C., se conoce una espada de hierro conservada completa, a excepción de una pequeña reconstrucción en el mango o espiga. La hoja es larga $(79 \mathrm{~cm})$, recta y de doble filo. El arriaz, en hierro también, es recto y de sección cuadrangular. El ancho de la hoja, en su conexión con el arriaz, es de $55 \mathrm{~mm}$.

Espada de Sevilla [Lám. VIIb]. Pertenece a los fondos del Museo Arqueológico de la ciudad y fue hallada en algún lugar de la provincia. Forjada en hierro, presenta una empuñadura con arriaz curvado y hoja ancha de canal central que cuenta con numerosos paralelos en el mundo vikingo. Se ha propuesto su data en el siglo X-XI, como posible importación franca, en concordancia con los datos que aportan las fuentes históricas contemporáneas que confirman la existencia de "espadas francas" como uno de los tipos presentes en Al-Andalus en el siglo $\mathrm{X}$, aunque sin descartar que se trate de una imitación andalusí de los modelos referidos, ya que sabemos de la imitación por parte del islam peninsular del armamento cristiano, aspecto éste que afectaba a la tipología y no al registro decorativo (NICOLLE y McBRIDE, 2001: 10-11; SOLER, 2001; SOLER, 1999: 107).

En cuanto a la identificación del arriaz de Los Algarbes con uno de los tipos de espadas citadas en las fuentes escritas andalusíes de época omeya ya aludidas, no es posible ante la vaguedad de las referencias, que apenas los nombran, sin más detalle: espadas francas, indias o árabes (SOLER, 1990: 171-173), incluso con la posibilidad de que dichas denominaciones de procedencia remitan, a su vez, a tipos diversos.
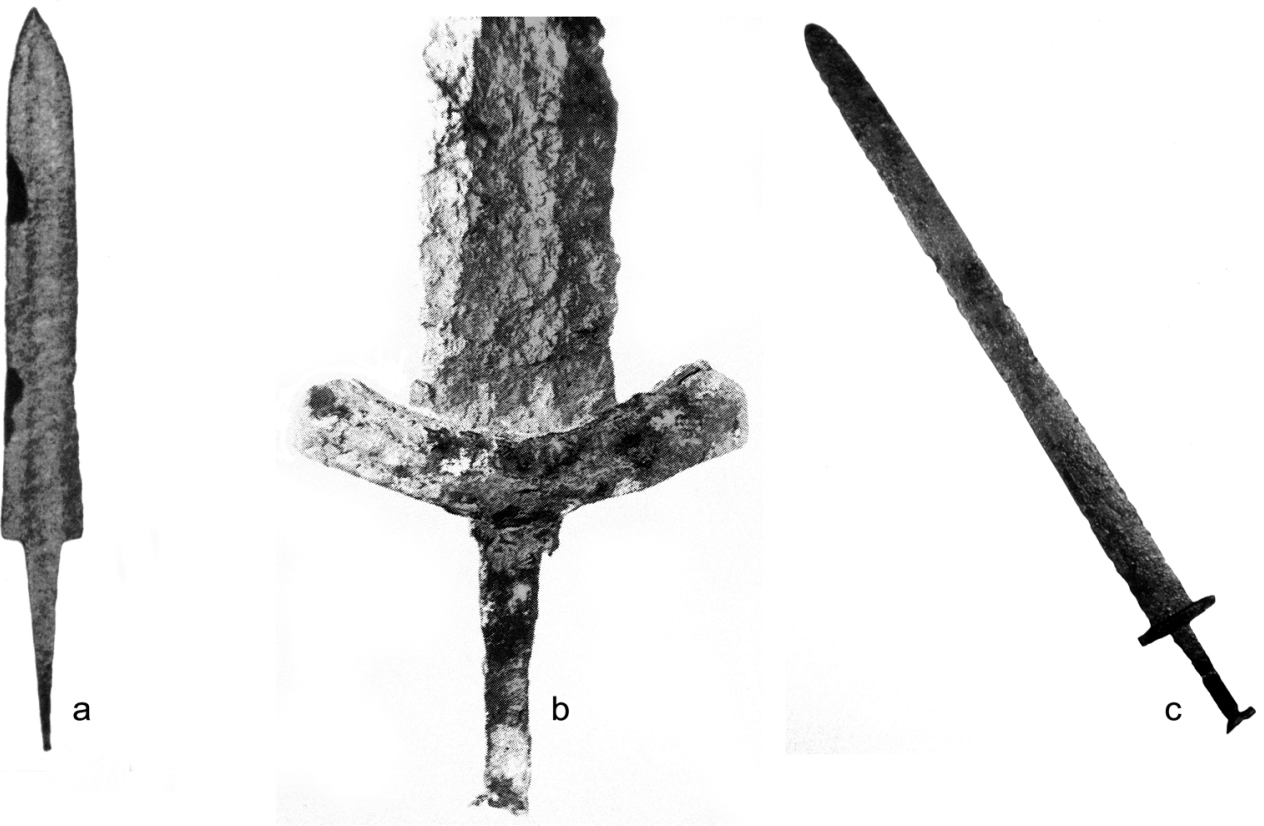

LÁM. VII: Espadas andalusíes de época omeya, a) Liétor (NAVARRO y ROBLES, 1996: XCI), b) Provincia de Sevilla (NICOLLE y McBRIDE, 2001: 10), c) Córdoba, con dudas (CANTO, 2001: fig. 2). Diferentes escalas. 


\section{INTERPRETACIÓN DEL MOTIVO ICONOGRÁFICO}

Ya hemos visto que la decoración del arriaz consiste en una sencilla composición que tiene su parte fundamental y central en una cabeza antropomorfa, dispuesta de frente, jalonada a ambos lados con un motivo vegetal de palmetas. Nos encontramos ante un tema figurado de un valor estético bastante limitado, de lo que tenemos que deducir que no ha sido empleado vanalmente, siguiendo la tradición islámica, sino que obedece a una intencionalidad que debe ir más allá de la capacidad decorativa de la representación. Es lógico pensar también que la cabeza ha de estar relacionada con la tipología y función del objeto, un arma para hacer la guerra. La decoración vegetal, que en una primera aproximación podríamos decir que no hace sino acompañar y embellecer el motivo central y, por extensión, el arriaz, también está dotada, como veremos más adelante, de un fondo interpretativo en consonancia con la figura antropomorfa.

Creemos que el arriaz de Los Algarbes muestra como decoración un motivo de la mitología islámica filtrado, en su diseño iconográfico, por la aculturación bizantina y, por ende, vinculado al mundo clásico.

Partiendo de este postulado, adelantamos que interpretamos la cabeza como perteneciente a un genio o ŷinn (ginn), en una manifestación claramente protectora del dueño de la espada en el desempeño de sus labores militares. Los ŷunūn, en la mitología islámica, son seres creados por Dios, masculinos y femeninos, situados en un escalafón entre los hombres y los ángeles (a veces, se confunden con éstos), inteligentes, imperceptibles a nuestros sentidos, y que pueden adoptar diferentes formas (de elemento natural -incluido el fuego y el agua, animal, vegetal o humana) y realizar proezas o trabajos extraordinarios. Fueron creados de fuego puro, o de vapores y humo y, al igual que los hombres, son mortales y se pueden reproducir. A través de magos y hechiceros pueden comunicar las decisiones divinas a los hombres: Salomón tenía fama de ser capaz de someter a estos genios. Los ŷunūn infieles, que también los hay, ya que gozan de libre albedrío, se condenarán en el infierno. La persona inspirada por un yinn podía adquirir conocimientos especiales, como en el caso del kahin o adivino, que se aprovecha de su supuesta unión con su espíritu protector o ŷinn para manifestar una voluntad divina.

Estas creencias en los genios están legitimadas por la sunna y el Corán, por lo que han formado parte de los credos y religiosidad populares, hasta tal punto que, en el caso de las personas iletradas, la fe y las prácticas islámicas pueden aparecer desfiguradas por las supersticiones derivadas de una inapropiada creencia en los ŷunūn. Éstos están presentes en todas las manifestaciones folklóricas del mundo musulmán y tal vez deban entenderse como una reliquia de cultos semíticos agrarios (MAÍlLO, 1996: 133, 264-265; THORAVAL, 1996: 310-311; GIL, 2004). Los ŷunün pueden estar al servicio de un objeto (como en el caso del arriaz de espada que nos ocupa) y actuar como protectores de las acciones de los humanos, aunque para lograr este objetivo se hayan visto obligados por el recurso de la magia (GIL, 2004: 88).

La aparición de los ŷunūn asociados a rituales de magia blanca de al-Andalus hubo de ser una constante, tal como deja deducir el manuscrito morisco misceláneo conocido como Libro de Dichos Maravillosos que, si bien se trata de una copia tardía de los siglos XVI-XVII, se ha argumentado que su contenido enraíza con la tradición mágica andalusí (LABARTA, 1993: 0.5 ss.). En esta obra se citan en torno a un centenar de nombres propios de $\hat{y} u n u \bar{n}$, que son invocados para tener participación activa en diversos procesos mágicos que buscan un beneficio para el solicitante o sus allegados, sus propiedades o sus intereses en general. El ỳinn del arriaz se convierte así en una suerte de talismán protector, al igual que lo era, por citar dos ejemplos, la desaparecida Puerta del Talismán de Bagdad [Lám. VIIIa] o el caldero de 


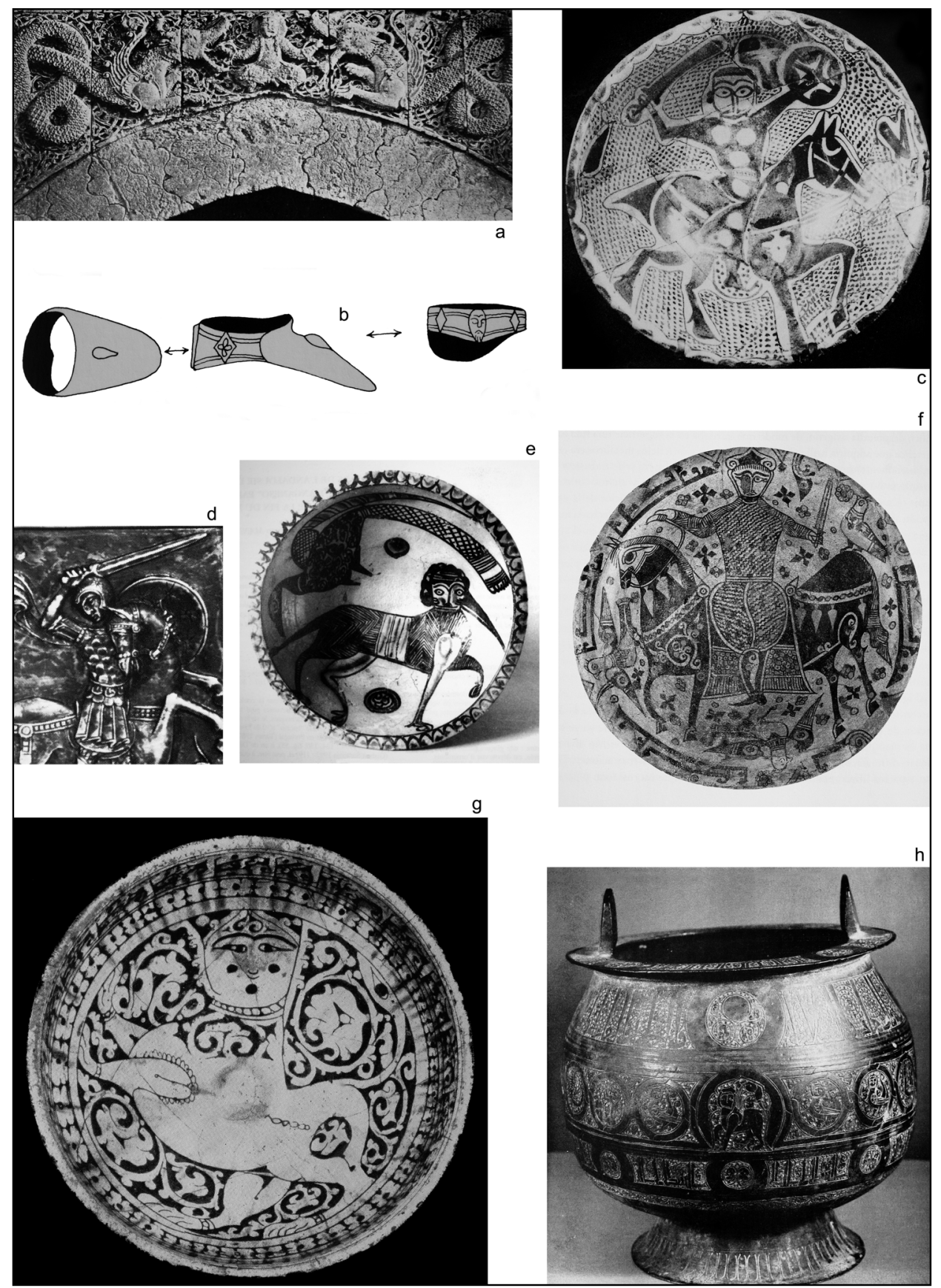

LÁM. VIII: a) Puerta del Talismán, desaparecida, en Bagdad (PIJOAN, 1954: 87), b) Anillo de arquero, con cabeza barbada, procedente de Egipto (NICOLLE y McBRIDE, 2000: 17), c) Cerámica iraquí con decoración de jinete portando una espada (NICOLLE y TURNER, 1998: 38), d) Detalle de la arqueta de los dos emperadores, con representación de espada de arriaz curvo (GALÁN, 2005:I, 69), e) Ataifor decorado de San Zeno, Pisa, con decoración de "león" o esfinge (BERTI, 2003: 41), f) Cerámica persa islámica con decoración de jinete portando una espada (HATTSTEIN y DELIUS, 2001: 121), g) Representación de esfinge en cerámica persa islámica (PIJOÁN, 1966: 297), h) Caldero de bronce de Herat con decoración de esfinges, harpías e inscripciones coránicas de buen agüero (PIJOÁN, 1966: 184). 
bronce con decoración de esfinges, harpías e inscripciones coránicas de buen agüero de Herat [Lám. VIIIh], ambos ejemplos también tardíos, aunque no posteriores al siglo XIII (PIJOÁN, 1966: 184).

Siguiendo esta interpretación que proponemos, como ŷunūn se han considerado las esfinges que aparecen, por ejemplo, en la cerámica medieval persa o siria. Estas esfinges, en cuanto recurso iconográfíco, son personajes benévolos, propiciatorios, portadores de buena suerte, ya que de otro modo no aparecerían formando parte de escenas positivas: coronación, desposorios, cacerías, etc. (PIJOÁN, 1966: 321-322). Precisamente, en la cabeza de alguna de estas esfinges tenemos un paralelo iconográfico del rostro del arriaz de Los Algarbes: en Oriente, una esfinge de un ataifor decorado procedente de Yastkand [Lám. VIIIg] (PIJOÁN, 1966: XX), y, en Occidente, en "el león" de un ataifor decorado, en verde y manganeso, de San Zeno (Pisa), importado desde Málaga o Denia [Lám. VIIIe] (BERTI, 2003: 41), de finales del siglo X o principios del XI. Aun con todo, las características del diseño (esquematismo en el rostro, unión de cejas y nariz formando un doble arco, etc.), no son ajenas a los modelos antropomorfos que podemos situar en la alta edad media, no sólo islámica, sino del entorno mediterráneo, por lo que este argumento ha de ser manejado con prudencia. Así, es frecuente, por ejemplo, en la cerámica bizantina.

Estos $\hat{y} u n u ̄ n$ orientales, también junto con los ángeles o malà'ika, tienen su punto de contacto con los genii latinos -la palabra árabe ŷinni podría proceder del latín genii, según algunos autores- y los daimones griegos (GUILLÉN, 1985: 65ss.), con los que comparten determinadas características que beben de un substrato cultural común o, al menos, interrelacionado y permeable. El genius en Roma era el numen (manifestación de la voluntad de algún dios) tutelar sobre los hombres y sobre las cosas. Así, por ejemplo, cuando un general partía para la guerra tomaba los auspicios con intención de cargarse de numen para la realización de aquella campaña. En tiempos de Imperio, todas las empresas militares se llevan a cabo bajo su correspondiente numen, sus auspicios o su genio. En la fe popular, el genius hace a la divinidad presente en todos los aspectos de la realidad, tanto en su faceta de conservadora como en la de productora (GUILLÉN, 1985: 67 y 68).

Por último, y no menos importante, la presencia de elementos vegetales en el arriaz, que se desarrollan a ambos lados de la cabeza central, parece no ser casual, o, al menos, estar plenamente justificada en concordancia con la interpretación que hacemos de la cabeza antropomorfa como cabeza de un ŷinn. La palabra ŷinn ( $\hat{g} i n n)$, según una propuesta discordante con la tesis que defiende su procedencia del término genius latino, derivaría de la raíz árabe $\hat{y} n n$ ( $\hat{g} n n)$, con el sentido etimológico propio de todo ser que está oculto, encubierto, escondido. Pero junto a este significado de encubrir o envolver, esta raíz ŷnn ( $\hat{g} n n)$ tiene otro de "crecer y desarrollarse en una rica vegetación, ser abundante y frondoso o hirsuto, cubrirse de una vegetación rica en plantas y flores". Este sentido de frondosidad se propone como el más antiguo ya que, en buena medida, la vegetación abundante tiene la capacidad de ocultar a la vista, tapar y proteger (GIL, 2004: 92). Dicho esto, parece evidente que nuestro ŷinn aparece medio oculto entre la vegetación, camuflado entre las hojas, coincidiendo a la perfección con la interpretación semántica que se le supone.

\section{PARALELOS ICONOGRÁFICOS DE LA DECORACIÓN}

Lo que sí es posible rastrear ya desde época romana es el esquema básico del diseño decorativo del arriaz, es decir, un motivo principal (que puede ser una cabeza o no) y las prolongaciones laterales de motivos vegetales. Así lo tenemos en el pulvinus con cabeza de Medusa del Museo de Historia de la Ciudad de Barcelona [Lám. IXa] (BELTRÁN, 2001: 20) o en mosaicos norteafricanos e hispanos (BLAZQUEZ, 2004; LÓPEZ, 2005: 305). Este 
esquema se mantendrá y diversificará en época bizantina, periodo éste del que beberá directamente la decoración de nuestro arriaz, como es el caso de algún friso decorativo copto del siglo V [Lám. IXc] (PIJOÁN, 1954: 138) en el que aparecen representadas "cabezas de geniecillos" escaqueadas entre roleos vegetales, o bien el más sincrético motivo decorativo que presenta una matriz bizantina metálica para la obtención de arreos decorados conservada en el Museo Nacional de Argel, datada en el siglo VI-VII [Lám. IXd] (EGER, 2003:415, t.71). Y aun le podemos seguir el rastro a esta composición en la iconografía de los pueblos bárbaros, con ejemplos tan significativos como los cimacios de la iglesia hispanovisigoda de San Pedro de la Nave (siglos VII-VIII), en Zamora, interpretados, desde una mística cristiana, como cabezas de ángeles, en concreto los siete que cita el Apocalipsis delante del trono de Dios [Lám. IXb] (BARROSO y MORÍN,1993: 89, 91 y 97). Sea como fuere, nos hallamos frente a la herencia de una fuerte tradición mediterránea a la que no han sido ajenas ningunas de sus orillas a lo largo de un dilatado periodo de tiempo. Así, no faltan ejemplos tampoco en el mundo carolingio o en el arte prerrománico. Éste es un caso frecuente en los estudios iconográficos tardoantiguos y altomedievales cuando "los motivos y escenas como las estudiadas encuentran su origen en la zona oriental del Imperio y fueron transmitidos a los artesanos de la antigüedad tardía tras un filtraje por los diferentes periodos y regiones, propiciando al mismo tiempo el desarrollo iconográfico del primer arte medieval” (RIPOLL, 1998: 91). La permanencia de los tipos, evolucionados y adaptados de un modo u otro, llegará hasta momentos tardíos, como podemos comprobar en la fachada de la iglesia bizantina de San Jorge en Jurjev-Pol'skoj (Rusia), del siglo XIII (VELMANS, KORAC y SUPUT, 1999: 430), o se expandirá geográficamente, caso de los rostros esquemáticos que aparecen en algunos arriaces de espadas vikingas (Museo de Oslo, de visu: arriaz de Gislevold, siglo IX-X d.C.).

En Al-Andalus, es altamente significativo que encontremos en la mezquita de Córdoba el esquema básico que venimos comentando, con su motivo central vegetal y no figurado, en los mosaicos decorativos de la cúpula central gallonada de la maqșüra, realizada en torno a 965 por Al-Hakam II [Lám. Xa]. En este espacio queda de manifiesto el dicho recurrente que sentencia que los omeyas no son sino bizantinos que hablan árabe. El motivo en cuestión lo encontramos en la cornisa u orla de los gallones, y está compuesto de un motivo central foliáceo coriforme del que parten, a ambos lados, sendas ramas vegetales con palmetas. El diseño de esta cornisa pertenece por el mismo derecho al arte bizantino y al arte musulmán (NIETO, 1998: 220), como se puede deducir tras el envío de un musivara por parte del emperador de Bizancio Nicéforo Focas a la corte cordobesa, tal como indican las fuentes históricas, para adiestrar a los artesanos locales en este arte.

Nos interesa reseñar aquí la coincidencia interpretativa, como representaciones de genios o ángeles -en todo caso seres sobrenaturales de marcado carácter religioso-, de las cabezas antropomorfas representadas en el friso copto (siglo V), también presentes en las telas del mismo periodo (PIJOÁN, 1954), y los cimacios de San Pedro de la Nave (siglos VII-VIII), ambos ya referidos, o en el conocido como Jarro de Balbarda y en algunas lucernas bizantinas (siglos IV-VII).

El Jarro de Balbarda, pieza de bronce expuesta en el Museo de Ávila, a caballo entre el mundo visigodo y el mozárabe (¿siglo IX?), presenta una decoración burilada que alterna figuras zoomorfas con otras de ángeles [Lám. IXe]. Estos últimos se representan como figuras antropomorfas de medio cuerpo o busto con alas, pero también como una cabeza sobre un motivo vegetal que se desarrolla de modo semejante a unas alas (VV.AA., 1989: s/p). Alas pseudovegetales muestra también el ángel que representa al evangelista San Mateo en la Biblia de León, del siglo X [Lám. IXh].

En el Museo Provincial de Lugo se conservan varios ejemplares de lucernas bizantinas de nuestro interés, los números 71, 72, 73, 74, 78 y 100 del catálogo de la Colección Varela Dafonte (CATÁLOGO, 2005: 85 a 88, 92 y 106). Todas ellas están catalogadas como lucer- 


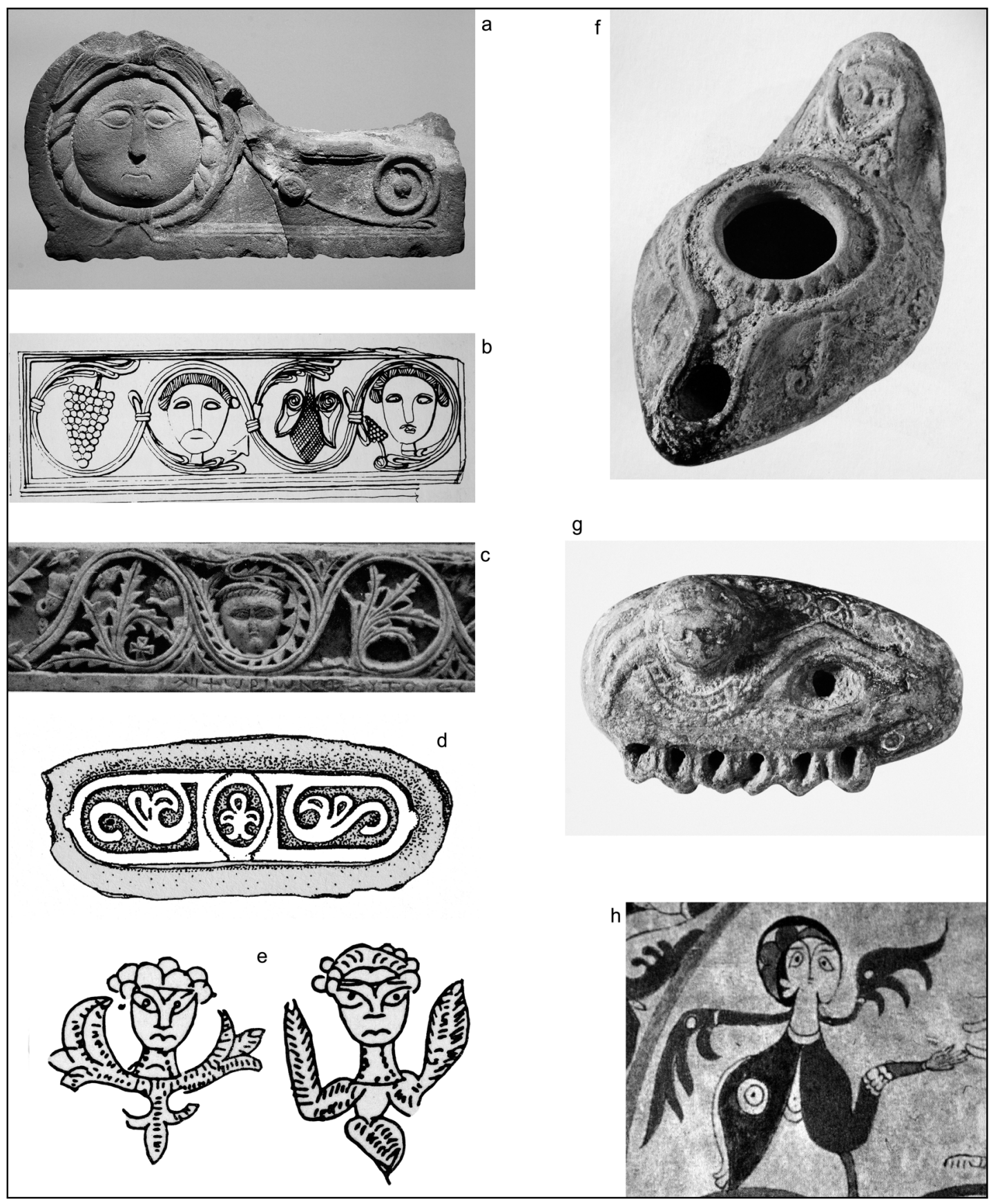

LÁM. IX: a) Pulvinus hispanorromano con cabeza de Medusa (BELTRÁN, 2001: 20), b) Cimacio hispanovisigodo de San Pedro de la Nave con decoración de cabezas de ángeles (BARROSO y MORÍN, 1993: 91), c) Friso copto con decoración de cabezas de geniecillos (PIJOÁN, 1954: 138), d) Matriz bizantina metálica para la obtención de arreos decorados (EGER, 2003: 415), e) Detalle de la decoración del Jarro de Balbarda, con representación de ángeles (VV.AA., 1989: s/p), f) Lucerna bizantina del Museo Provincial de Lugo, con decoración de cabeza antropomorfa en el asa (CATÁLOGO, 2005: 86, cat. 72), g) Lucerna bizantina del Museo Provincial de Lugo, con decoración interpretada como representación de un posible ángel (CATÁLOGO, 2005: 106, cat. 100), h) Representación de ángel (San Mateo evangelista), en la Biblia de León (BANGO, 2001: 550). 
nas bizantinas (la $\mathrm{n}^{\circ} 100$ con algunas dudas) que podemos fechar entre el siglo IV y principios del siglo VII. Los cinco primeros ejemplares corresponden a lucernas de canal, características de la época romana tardía, que se caracterizan por sus cuerpos piriformes y por la presencia de un canal que enlaza el cuerpo con el pico (CATÁLOGO, 2005: 148). Estas lucernas presentan un asa alta, maciza y sobreelevada decorada con motivos geométricos, vegetales, la cruz cristiana o un rostro esquemático humano [Lám. IXf], algunos de ellos engalanados con las coronas con pendientes pingantes bizantinos, similares a los que portan Justiniano y Teodora en los mosaicos de San Vital de Rávena. En general, se aprecia una decoración marcadamente religiosa. Aunque no se han interpretado específicamente estos rostros, sí se ha apuntado que podrían ser una representación del emperador en cuanto representante de Dios en la tierra, lo que nos orienta, de nuevo, hacia el sentido religioso de los mismos. Hay dos ejemplares ( $\mathrm{n}^{\mathrm{o}} 72$ y 74 ), claramente sin corona ni pendientes en uno de los casos, y sólo con posibles pendientes en el otro, que son los que presentan una mayor similitud con el motivo representado en el arriaz de Los Algarbes y que, creemos, podrían no interpretarse del mismo modo que el resto, ya que faltan los argumentos de indumentaria aducidos. La respuesta interpretativa para estos dos podría estar en una sexta lucerna, no 100 [Lám. IXg], distinta tipológicamente a las demás. Se trata de una lucerna ovalada, con siete mechas, y decorada con "la cabeza, en alto relieve, de un personaje, al parecer joven (¿un ángel?) engalanado con un collar o cenefa perlada, doble, que alza el brazo izquierdo protegiendo un pequeño agujero de aireación en depresión. A su derecha pueden verse diversos relieves redondeados que parecen posibles alas" (CATÁLOGO, 225: 153).

Dentro de un arte estrictamente islámico en su manufactura, debemos traer aquí un paralelo del esquema de cabeza centralizada jalonada de elementos vegetales en un bote de marfil de fabricación cordobesa de finales del siglo X, con una tapa añadida con posterioridad (¿siglo XI?), quizás en la Italia meridional [Lám. Xe] (GALÁN, 2005: II, 45-46). Es el conocido como bote Bèarn-Béhague, del Museo Nacional de Kuwait. En la tapa conservada, que sustituye a la original perdida, y es ajena como ya hemos referido al arte califal cordobés, pero no al arte islámico, se muestra un friso decorativo articulado por un grueso cordón que deja espacios triangulares, en dos de los cuales se representan sendas cabezas antropomorfas flanqueadas a ambos lados con motivos vegetales. También hallamos cabezas similares en la decoración del olifante Bassilewsky del Museo del Hermitage de San Petersburgo, a decir de los investigadores, detalle que no hemos tenido la oportunidad de contrastar. En el caso del bote, proponemos la identificación de las cabezas, al abrigo de lo interpretado para el arriaz de Los Algarbes, como representaciones de ŷunûn, a pesar de que hasta ahora no han sido identificados tales seres fantásticos en la decoración de marfiles, aun reconociendo su carácter "casi omnipresente" (GALÁN, 2005: I, 308). No deben confundirse con estas representaciones otras similares de cabezas antropomorfas que, acertadamente creemos, son interpretadas de modo más convencional, como en el caso de la arqueta del Museo Victoria \& Albert, de Longhurst (ss. X-XI), donde la cabeza encajada sobre un camello puede leerse como perteneciente a una novia dentro de un palanquín nupcial (GALÁN, 2005: II, 56).

Un caso peculiar, dentro también de la eboraria, lo tenemos en las dos cabezas, de rasgos zoomorfos, talladas en la conocida como Cruz de San Millán, de finales del siglo X, vinculada de un modo u otro a los talleres cordobeses, y que son definidas, en su novedad iconográfica, como "mascarones animalescos, sin precedentes musulmanes, aunque pueden encontrarse en el arte romano y en el románico" (GALÁN, 2005: II, 102).

Para cerrar este apartado, no debemos dejar de referir aquí la representación islámica, no andalusí, de una cabeza humana barbada, formando parte de la decoración de una púa broncínea de arquero, procedente de Egipto, y datada entre el 750 y el 850 d.C. [Lám. VIIIb ] (NICOLLE y McBRIDE, 2000: 17). 


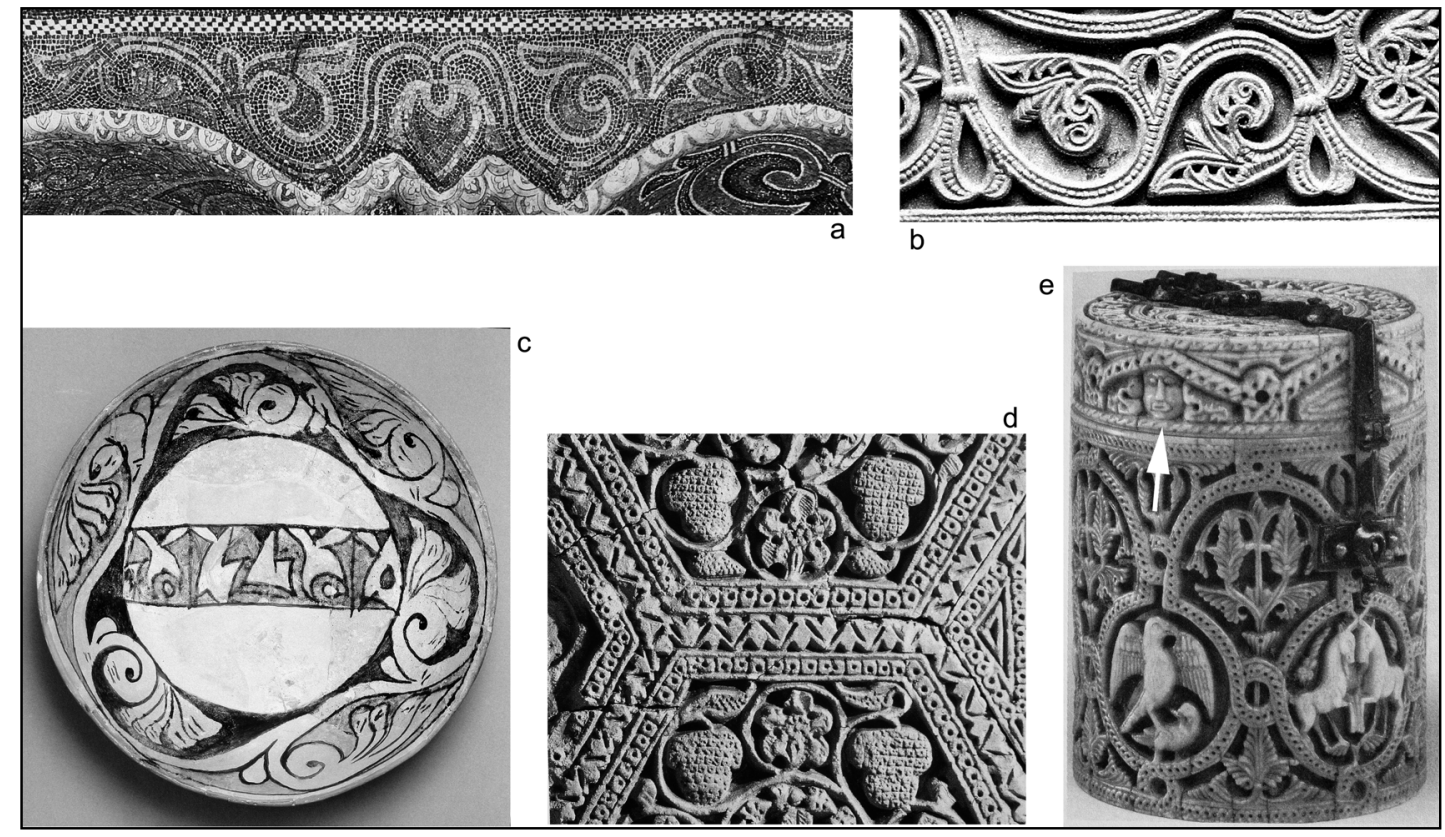

LÁM. X: a) Detalle de la decoración de la cúpula gallonada del al-Hakam II, en la mezquita de Córdoba, b) Detalle de la decoración parietal de una de las estancias anexas al salón de 'Abd al-Rạ̣man III, en madinnat al-Zahrā' (VALLEJO, 1987: 160), c) Ataifor cordobés con decoración de palmetas (CATÁLOGO, 1992: 232), d) Estuco decorativo de Samarra (HATTSTEIN y DELIUS, 2001: 95), e) Bote Bèarn-Béhague de marfil con cabeza antropomorfa y motivos vegetales en la tapa (GALÁN, 2005: II, 45).

En cuanto a la decoración vegetal del arriaz, palmetas vegetales con tallo sinusoide, pertenece al grupo de las "palmetas y roleos" individualizado por Pavón (PAVÓN, 1990: 111112). Según este autor, "la cenefa estrecha con palmetas asidas a roleos ondulados encuentra ya amplia acogida en el arte sasánida, el bizantino y en el omeya oriental; se impone sobre todo en Madinat al-Zahra y en la Mezquita Mayor de Córdoba, de donde pasaría a la Aljafería de Zaragoza y al arte almorávide. Desciende su uso notablemente en el arte nazarí, el mariní y el mudéjar". Las diferencias estilísticas en la ejecución suelen estar asociadas a cronologías diversas. En nuestro caso, los paralelos nos remiten a los modelos arquitectónicos de época omeya que podemos observar en madinat al-Zahrā' o en los restos procedentes de la mezquita mayor de Tudela, o a la decoración cerámica de los ataifores decorados en verde manganeso de la ciudad palatina [Lám. Xc]. Una peculiaridad de las palmetas del arriaz es la decoración interior de las hojas de un modo concreto, usando nuevas hojas interiores de menor tamaño, lo que da la apariencia de unas hojas dentro de otras. Este rasgo lo tenemos perfectamente testimoniado, por ejemplo, en la decoración parietal de las estancias privadas anexas al Salón de 'Abd al-Rạ̣man III de madīnat al-Zahrā' [Lám. Xb] (VALLEJO, 1987: $147,151,160$ ) con una data que se puede situar entre los años 953 y 966 d.C. ${ }^{2}$

Un aspecto de interés nos viene señalado por la decoración de los tallos que enlazan una palmeta con otra. Forma un motivo de cadeneta con anillos alargados, semejantes a eslabones sin enlazar, con punto central inciso, enmarcados entre dos líneas. En el arte califal cordobés de madinat al-Zahrā' no tenemos paralelos exactos, presentándose generalmente estos

2 Agradecemos a Lola Luna y Ana Zamorano respectivamente, sus oportunas apreciaciones sobre las palmetas de madinat al-Zahrā' con decoración interior. 
elementos como botones circulares (lisos o con concavidad central o protuberancia, también centrada). Será en Samarra, la capital abasí, en sus estucos decorativos [Lám. Xd], donde sí encontremos paralelos de nuestra secuencia y tipo (PAVÓN, 1989: 62, 63 y 67-69), dentro del conocido como "primer estilo", lo que nos vuelve a relacionar con la influencia oriental tan característica del arte omeya cordobés. Si en Samarra este motivo decorativo está fechado en el siglo IX, su pervivencia está demostrada como influencia directa del arte de la capital abasí, y así lo tenemos en el siglo siguiente, a principios o mediados del siglo X, por ejemplo, en la gran mezquita de Nayin, también en Irán (HATTSTEIN y DELIUS, 2001: 105ss.), si bien esta influencia se extiende desde Asia central al norte de África.

Con este rápido repaso concluimos que el motivo decorativo del arriaz de Los Algarbes es de tradición mediterránea oriental, bizantina, con influencias abasíes, adoptado, como tantas otras cosas, por los omeyas de occidente, aunque no por ello deja de representar un motivo genuino de la mitología islámica. Creemos que se trata de una manufactura andalusí, muy probablemente califal, pero sin descartar su pertenencia a un periodo inmediatamente anterior (emirato) o posterior (siglo XI) a este momento. No debemos desestimar, de igual modo, que se trate de una "importación" bizantina o fatimí, pues el tipo iconográfico, como hemos visto, no nos permite ser categóricos.

Tampoco debemos olvidar que, en el estado actual de conocimiento, "la normalización y generalización de los procesos de extracción, fundición y producción de los metales serán paralelos y coetáneos a la consolidación del estado islámico en al-Andalus, como así sucedió en el Egipto Fatimí, y no es anterior al siglo X" (AZUAR, 1998: 54), por lo que podríamos proponer el siglo X como el más adecuado para el arriaz de Los Algarbes. Precisamente, para el siglo $\mathrm{X}$, conocemos la existencia de un taller de artesanía que fundía objetos de bronce en Córdoba y, posiblemente, otro en medina Elvira. El caso del taller cordobés está perfectamente atestiguado por el registro arqueológico ya que la firma de un tal Rashiq aparece, al menos, sobre un candil de la conocida ocultación de Liétor (NAVARRO y ROBLES, 1996: 77-78) y en seis dedales procedentes del entorno cordobés (AZUAR, 1998: 44ss). Este Rashiq estuvo en activo en el segundo cuarto del siglo $\mathrm{X}$ y es el mismo que trabajó en madinat al-Zahrā' o en las obras de ampliación de la mezquita cordobesa. Precisamente, en madīnat al-Zahrā' tenemos constancia de la existencia de talleres artesanos para la fabricación de armas, joyas y objetos de pedrería (TORRES, 1987: 746). El supuesto taller de Elvira, o de su entorno, se ha asociado a una serie de candiles en bronce con un asa de un tipo característico, al que pertenece el asa de candil de Los Algarbes, el mismo yacimiento del que procede el arriaz (v.supra).

Queda de manifiesto, entonces, la existencia en la Córdoba del siglo X, y quizás también en Elvira, de talleres artesanos capaces de realizar una manufactura metálica como la del arriaz de los Algarbes, sin duda de menor complejidad tecnológica, en su fabricación, que los candiles, y sin tener que recurrir, en consecuencia, a importaciones de ningún tipo para justificar su presencia en el entorno cordobés.

\section{Otros genios en al-Andalus: una propuesta de identificación}

Llegados a este punto, podemos preguntarnos si se han empleado otras representaciones similares -cabezas antropomorfas que podamos considerar como de genios o ŷnun- en objetos susceptibles de ser protegidos o beneficiados en algún modo (ellos, su contenido o sus usuarios) en un contexto histórico andalusí. Creemos que la respuesta es positiva y aportamos los siguientes ejemplos, si bien algunos de ellos hemos de considerarlos, por el momento, como hipótesis de trabajo:

Talismanes de plomo figurados [Lám. XIa y XIb]. Dentro de la variopinta tipología de talismanes conocidos en Al-Andalus, fundidos en plomo, se encuentran varios figurados. Una 


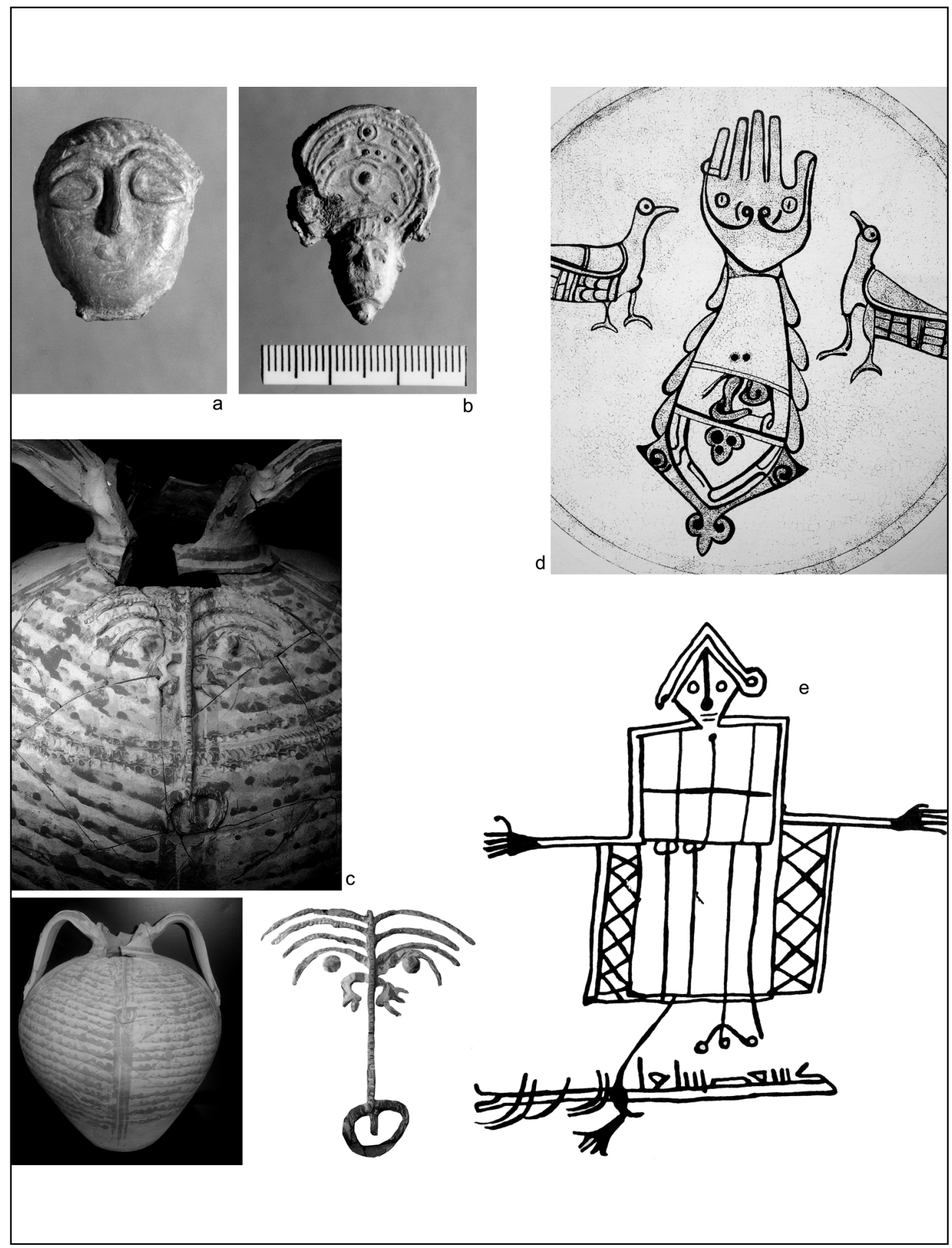

LÁM. XI: a) y b) Talismanes de plomo figurados andalusíes, inéditos (Museo Histórico Municipal de Priego de Córdoba y colección particular), c) Jarra andalusí de Lucena, inédita (Museo Arqueológico y Etnológico de Lucena), d) Ataifor de Alarcos, detalle de la decoración (RETUERCE y GARCÍA, 1999: 260), e) Representación del ŷinn Barqân según el Libro de Dichos Maravillosos (LABARTA, 1993: 182). 
de ellas representa una cabeza antropomorfa que suele estar tocada por un gorro o aureola, y que constituye el tipo II.A.a de Gozalbes, de los ejemplares estudiados por este autor para la provincia de Málaga (GOZALBES, 2003: 351, 358, 360). Este mismo investigador presenta el tipo I.B.e, o pequeña "anforita" de boca ancha $(3 \mathrm{~cm}$ x 3,8 cm), con una cara de "rasgos primitivos (ojos almendrados)" en el galbo. El pelo forma las asas. Nosotros aportamos dos ejemplares más, inéditos. Uno, depositado en el Museo Histórico Municipal de Priego de Córdoba, procede del yacimiento arqueológico del Cortijo de las Alcabalas (Priego de Córdoba), asentamiento rural andalusí con una ocupación mínima constatada para época almorávide-almohade. Está incompleto y representa un rostro antropomorfo esquemático. Y un segundo, procedente de Charilla (Alcalá la Real, Jaén), conservado en una colección particular, de similares características al prieguense, pero que conserva la aureola. La cronología de estos talismanes es incierta, al proceder de hallazgos descontextualizados. De forma general, con las cautelas oportunas, podría servirnos como primera referencia la datación atribuida al yacimiento del Cortijo de las Alcabalas de Priego.

Jarra de Lucena (Córdoba) [Lám. XIc]. Pintada con trazos rojos y con decoración aplicada. En el Museo Arqueológico y Etnológico de Lucena (Córdoba) ${ }^{3}$ se conserva un gran contenedor cerámico inédito, ingresado en 2002, procedente del casco urbano de la ciudad, de un solar de la calle Las Tiendas, extramuros del recinto amurallado de la ciudad medieval pero próximo a la puerta de Aguilar. Se trata de una jarra con decoración convencional pintada en rojo a la que se ha añadido un motivo inusual, en relieve, realizado con un cordón de barro aplicado, que dibuja un rostro antropomorfo esquemático, disimulado y semioculto intencionadamente tras la apariencia de una palmera datilera. Esta decoración, del todo excepcional, ha de tener un valor profiláctico o transformador del contenido del recipiente (en principio, agua) en relación a las virtudes atribuidas a la cabeza del ŷinn representado, de modo similar a lo que se indica en el misceláneo morisco Libro de Dichos Maravillosos, cuando se dibuja la imagen del genio Barqân en el exterior de un vaso para dotar a éste de virtudes mágicas (LABARTA, 1993: 11), o en el caso del rostro representado en los talismanes de plomo con forma de "anforita" referidos en el apartado anterior. La apariencia disimulada del ŷinn podría interpretarse como un recurso ingenioso para ocultar una figuración que, al fin y al cabo, es objeto de recelo en el mundo islámico, o bien, lo que nos parece más acertado, corresponder a un juego visual derivado de la creencia de que los ŷunūn pueden adoptar, en cuanto seres mágicos, formas diversas, y, en todo caso, son criaturas que se ocultan y camuflan. Su vinculación con el agua es, además, conocida, ya que pueden habitar en estanques, fuentes, pozos o manantiales, y así, en la Arabia preislámica, se realizaban sacrificios a los ŷunūn cuando se descubría un manantial (GIL, 2004: 87-89 y 94). Tampoco este doble sentido figurativo mostrado es algo extraño al islam y es una característica, por ejemplo, del periodo de los abasíes, y lo vemos plasmado en la decoración cerámica contemporánea al mismo. Cronológicamente situamos este ejemplar de Lucena en torno al siglo XII, ya en época almohade, según información facilitada por el director del museo y que parece coherente con otras cerámicas relacionadas (decoración de cuerda seca parcial, ataifor carenado, decoración verde y manganeso asociada a pie anular, etc.). En el Museo Arqueológico de Ammán (Jordania) se conserva un gran recipiente con decoración aplicada que alterna unas representaciones realistas con diversos medallones de rostros esquemáticos, de factura similar a los que estamos tratando, y que se han fechado en el periodo omeya tardío (siglo VIII). Esta vasija, de múltiples asas, ha sido vinculada a "una función más bien ceremonial que doméstica o fue concebida para un propósito doméstico muy particular" (ZAYADINE, KEHRBERG y BISHEH, 2000: 67.).

3 Agradecemos a su director, Daniel Botella, la información facilitada, así como las fotografías de este interesantísimo recipiente cerámico. 
Ataifor de Alarcos (Ciudad Real) [Lám. XId]. Conservado en el Museo de Ciudad Real. Este recipiente cerámico, decorado en verde y manganeso, presenta en su parte central un motivo decorativo simbólico consistente en un brazo derecho con la palma de la mano vuelta hacia el espectador, con anillo en el meñique, y flanqueada por dos aves posadas. Nuestro interés en esta decoración reside en que la palma de la mano ha sido dibujada como un rostro antropomorfo esquemático en el que se reconocen perfectamente los ojos y la nariz, y que proponemos que podría tratarse de la representación de un ŷinn. Para Retuerce y García (RETUERCE y GARCÍA, 1999: 246-248, 260), nos encontraríamos ante la mano y la faz de Dios, aun reconociendo la heterodoxia religiosa de esta interpretación. Nosotros proponemos una relectura en base a los argumentos que estamos manejando. El ataifor de Alarcos tendría un valor talismánico, en el que la mano o brazo se asemejaría a la hamsa "cinco", como elemento protector, tal como aparece en la puerta de la Justicia de la Alhambra (1348), por otra parte de gran parecido formal con el brazo representado en el ataifor. El anillo, en su significado mágico de atar y unir, no haría sino redundar sobre estos valores, no en vano los ŷunün pueden ser referidos en la narrativa oral árabe como "servidores del anillo o de talismanes" (GIL, 2004: 88 y 89). La mano, representada con el antebrazo, se identifica con la divinidad o el poder celestial, símbolo de la Providencia divina, asociada a la idea de protección (CAVILLA, 2005: 314). El rostro antropomorfo estaría representado con la misma indefinición y dualidad con que aparece en la jarra de Lucena (Córdoba), y por los mismos motivos que hemos expuesto para el caso cordobés. El ataifor de Alarcos está fechado en época almohade, en concreto entre 1195 y 1212 (RETUERCE y GARCÍA, 1999: 241). Precisamente, es en época almohade cuando prolifera en Al-Andalus el motivo de la hamsa o mano de Fátima como decoración cerámica (CAVILLA, 2005: 314-317): la vemos como estampilla bajo vidriado, con un ojo en la palma tal como es tradicional actualmente en el mundo árabe (CARMONA, 1992: 71; MORRIS, 2001: 190-191), o como decoración esgrafiada (CRESPO, 2001: 364-365) y, ya más tardíamente, como recurso iconográfico de las cerámicas mudéjares, de Teruel o Paterna, por ejemplo (CATÁLOGO, 2002a: 238; CATÁLOGO, 2002b: 196). Su presencia en la cerámica esgrafiada ha sido interpretada como elemento ritual, purificador, quizás destinado a contenedores de agua utilizados en las abluciones de la oración de los viernes. (CRESPO, 2001: 366). Como argumento final para la reinterpretación del ataifor de Alarcos, aportamos la hamsa esgrafiada, fechada en el siglo XIII, parcialmente conservada como fondo de un ataifor procedente de Lorca (Murcia), y que presenta dos ojos en la base de la palma y un motivo decorativo entre ambos que se prolonga por el brazo que la asemejan a un rostro antropomorfo (CATÁLOGO, 1986: 84). En la actualidad, la presencia de un ojo en la popular mano de Fátima se entiende como "protección complementaria del ojo que hace bajar la vista al mal de ojo y a veces recibe el nombre de ojo de Maat" (MORRIS, 2001: 191). ¿Podemos identificar este Maat con el ŷinn Mațațat que aparece en el Libro de Dichos Maravillosos? (LABARTA, 1993: 89). En todo caso, el concepto de maat, con esta denominación, aparece ya en la religión egipcia, donde se entiende como representación del principio del mundo estructurado, es decir, el orden y el equilibrio, los valores éticos y la justicia, la cultura y la fuerza creadora. Es lo opuesto a lo desordenado y salvaje y a lo destructivo e injusto. La divinidad que personificaba este principio recibió su mismo nombre (SCHULZ y SEIDEL, 1997: 522

Libro de Dichos Maravillosos [Lám. XIe]. Ya hemos hecho referencia a este misceláneo morisco de magia y adivinación. Lo traemos a colación ahora porque tanto en el Libro de Dichos Maravillosos propiamente dicho como en el Libro de los Talismanes y de sus Reglas, que forma parte de este recopilatorio, se ha representado, en dos ocasiones, la figura del genio o ŷinn Barqân, en los folios 22v y 531r respectivamente (LABARTA, 1993: 11 y 182). En los dos casos se muestra de cuerpo entero, de modo esquemático, si bien en el segundo caso los rasgos antropomorfos están más acentuados. Estas figuras debían dibujarse tal como se las 
representa en el manuscrito, y se las empleaba en talismanes y filtros (disoluciones mágicas). Con ello se pretendían obtener múltiples favores: amorosos, de protección ante el mal, de curación, adivinatorios, etc. Aun tratándose este manuscrito de una copia tardía (siglos XVIXVII), la similitud iconográfica del tipo se mantiene.

Varios. Sin duda, habrá en la cultura material andalusí conocida más elementos antropomorfos de este tipo que pudieran compartir interpretación, en algún modo, con los que estamos refiriendo aquí. Un ejemplo de ello podría ser los objetos de hueso, cilindricos torneados, que se asemejan a una figura antropomorfa en la que destaca la parte de la cabeza con un rostro de similar factura a los de nuestro interés. Aunque la funcionalidad de estos objetos está por definir satisfactoriamente -no creemos que sean simples juguetes-, el valor protector supuesto a la decoración antropomorfa sería compatible y en virtud de la misma. Cronológicamente, los ejemplares conocidos han sido fechados entre los siglos X y XIII, si bien en el ámbito cordobés el predominio de los hallazgos es para época califal (RUIZ, 2001: 393).

\section{BIBLIOGRAFÍA}

ALEXANDER, D. (2001): "Swords and sabers during the early islamic period", Gladius, XXI, pp.193-220.

AZUAR RUIZ, R. (1998): "Bronces litúrgicos y la formación de Al-Andalus", Cuadernos Emeritenses, 15, pp.29-54.

BANGO TORVISO, I.G. (2001): Arte prerrománico hispano. El arte en la España cristiana de los siglos VI al XI, Summa Artis, VIII-II, Madrid.

BARROSO CABRERA, R. y MORÍN DE PABLOS, J. (2003): El árbol de la vida. Un estudio de iconografía visigoda: San Pedro de la Nave y Quintanilla de las Viñas, Madrid.

BELTRÁN DE HEREDIA BERCERO, J. [dir.] (2001): Los restos arqueológicos de la plaza del Rey de Barcelona. De Barcino a Barcinona (siglos I-VII), Barcelona.

BERTI, G. (2003): "Pisa-spagna: importazioni di materiali e di conoscence tecniche nei secoli X-XIII", Cerámicas islámicas y cristianas a finales de la Edad media. Influencias e intercambios, Ceuta.

BLÁZQUEZ MARTÍNEZ, J.M". (2004): "Máscaras humanas en roleos de mosaicos en Oriente, África e Hispania", L'África Romana, 15 (vol.2), Atti del XV convengo de studio, Tozeur, 11-15 December 2002, pp.1023-1038.

CABRERA LAFUENTE, A. (2005): "Los tejidos como patrimonio: investigación y exposición", Bienes Culturales, 5, Tejidos hispanomusulmanes, pp.5-19.

CAMACHO CRUZ, C.; HARO TORRES, M.; LARA FUILLERAT, J.M. y PÉREZ NAVARRO, C. (2004): "Intervenciones arqueológicas de urgencia en el arrabal hispanomusulmán Casas del Naranjal. Yacimiento O. Ronda Oeste", Anuario Arqueológico de Andalucía, 2001, III, Vol. I, pp.210-230, Sevilla.

CANTO GARCÍA, A. (2001): "Una espada de época omeya del siglo IX d.C.", Gladius, XXI, pp.183-192.

CARMONA AVILA, R. (1992): "Nuevos datos sobre el sistema defensivo de Madinat Baguh durante la Edad Media", Antiqvitas, 3, pp.62-71.

CAVILLA SÁNCHEZ-MOLERO, F. (2005): La cerámica almohade de la isla de Cádiz (Yazirat Cádiz), Cádiz.

CATÁLOGO (1986): La cerámica islámica en Murcia, I, Catálogo, Murcia.

CATÁLOGO (1992): Al-Andalus. Las artes islámicas en España, Madrid.

CATÁlOGO (2000): Las Andalucías. De Damasco a Córdoba, París.

CATÁLOGO (2002a): ... Operis terre turolii. La cerámica bajomedieval en Teruel, Teruel.

CATÁLOGO (2002b): La cerámica de Paterna. Reflejos del mediterráneo, Valencia. 
CATÁlOGO (2005): Ilumina. Colección de lucernas José Antonio Varela Dafonte, Lugo.

CÓRDOBA DE LA LLAVE, R. y HERNÁNDEZ ÍÑIGO (1994): "Dedales hispano-musulmanes en la provincia de Córdoba", Actas IV Congreso de Arqueología Medieval Española, Tomo III, pp. 919-925, Alicante.

CRESPO PACUAL, A. (2001): "Cerámica esgrafiada. Estado de la cuestión", Anales de Arqueología Cordobesa, 12, pp.7-11.

DURÁN, V. y PADILLA, A. (1990): Evolución del poblamiento antiguo en el término municipal de Écija, Écija.

FROCHOSO SÁNCHEZ, R. (2001): Los feluses de al-Andalus, Madrid.

GOZALBES CRAVIOTO, C. (2003): "Hallazgos de amuletos de plomo andalusíes en la provincia de Málaga", Actas del III Congreso de Historia de Andalucía, Andalucía Medieval (I), Córdoba, pp. 343-362.

EGER, C. (2003): "Reiten auf delphinen. Byzantinische pressblechmodel für sattel-und zaumzeugbeschläge aus dem Nationalmuseum von Algier", Madrider Mitteilungen, 44, pp. 412-425.

FAGNEN, C. (2005): Armement médiéval. Un métal pour la guerre, Lonrai.

FUERTES SANTOS, Ma C. (2002): La cerámica califal del yacimiento de Cercadilla, Córdoba, Sevilla.

GALÁN Y GALINDO, A. (2005): Marfiles medievales del islam, Vol.I y II, Córdoba.

GIL GRIMÁN, R. (2004): "Una cierta sistematización de la demonología árabe y sus orígenes (I)", Boletín de la Asociación Española de Orientalistas, XL, pp.85-99, Madrid.

GUILLÉN, J. (1985): Urbs Roma. Vida y costumbres de los romanos, III, Religión y ejército, Salamanca.

HATTSTEIN, M. y DELIUS, P. (ed.) (2001): El Islam. Arte y Arquitectura, Colonia.

HEATH, I. y McBRIDE, A. (2002): Byzantine Armies (886-1118), Men-at-Arms, 89, Oxford.

LABARTA, A. (1993): Libro de Dichos Maravillosos. Misceláneo morisco de magia y adivinación, Madrid.

LÓPEZ RUIZ, U. (2005): "Hallazgo de un mosaico de temática estacional en Astigi (Ecija, Sevilla)", SPAL, 14, pp.301-313.

MAÍlLO SALGADO, F. (1996): Vocabulario de historia árabe e islámica, Madrid.

MARTÍNEZ CASTRO, A. (2002): "Evolución de las Tierras Occidentales. Un recorrido por la historia de Los Algarbes", La Carlota. Libro de Feria 2002, pp.107-118.

MARTÍNEZ CASTRO, A. (2005): "El tramo de la Via Augusta entre Corduba y Astigi. Una aproximación de detalle a su recorrido y características constructivas", Antiqvitas, 17, pp.57-70.

MARTÍNEZ ENAMORADO, V. (2003): "La Algarbía como realidad geo-histórica en el periodo de formación de Al-Andalus. Una aproximación al estudio de su poblamiento rural", Actas Arqueología y Patrimonio en la Algarbía malagueña, Málaga, pp. 57-94.

MARTÍNEZ ENAMORADO, V. (2005): "La espada de protocolo del sultán nazarí Muhammad V", Gladius, XXV, pp. 285-310.

MEDINA GÓMEZ, A. (1992). Monedas hispano-musulmanas, Toledo.

MELCHOR GIL, E. (1995): Vías romanas de la provincia de Córdoba, Córdoba.

MORRIS, D. (2001): Guardianes del cuerpo. Amuletos y objetos protectores, Barcelona.

MONTOYA TEJADA, B. (1979): Marfiles cordobeses, Córdoba.

NAVARRO PALAZÓN, J. y ROBLES FERNÁNDEZ, A. (1996): Liétor. Formas de vida urales en Sarq al-Andalus a través de una ocultación de los siglos X-XI, Murcia.

NIETO CUMPLIDO, M. (1998): La catedral de Córdoba, Córdoba.

NICOLLE, D. (2002): "Two swords from the foundation of Gibraltar", Gladius, XXII: 147-200.

NICOLLE, D. y McBRIDE, A. (2001): The moors. The islamic west $7^{\text {th }}-15^{\text {th }}$ centuries AD, Men-at-arms, 348, Oxford. 
NICOLLE, D. y TURNER, G. (1998): Armis of the caliphates (862-1098), Men-at-arms, 320, Oxford.

PAVÓN MALDONADO, B. (1989): El arte hispano-musulmán en su decoración geométrica, Madrid.

PAVÓN MALDONADO, B. (1990): El arte hispano-musulmán en su decoración floral, Madrid.

PEIRCE, I. (2002): Swords of the viking age, Woodbridge.

PIJOÁN, J. (1966): Arte islámico, Summa Artis, XII, Madrid.

PIJOÁN, J. (1954): Arte cristiano primitivo. Arte bizantino, Summa Artis, VII, Madrid.

RETUERCE, M. y GARCíA, A. de J. (1999): "La cerámica almohade en verde y manganeso de la meseta", Arqueología y Territorio Medieval, 6, Actas del coloquio La cerámica andalusí, 20 años de investigación, pp. 241-260, Jaén.

RETUERCE VELASCO, M. (1998): La cerámica andalusí de la Meseta, Vol. I-II, Madrid.

RIPOLL LÓPEZ, G. (1998): Toréutica de la Bética (siglos VI y VII d.C.), Barcelona.

RUIZ NIETO, E. (2001): "Representaciones antropomorfas hispanomusulmanas sobre hueso", Anales de Arqueología Cordobesa, 12, pp. 385-396.

SCHULZ, R. y SEIDEL, M. [ed.](1997): Egipto. El mundo de los faraones, Colonia.

SOLER DEL CAMPO, A. (1990): "El armamento en época omeya", Madrid del siglo IX al $X I$, pp. 171-187.

SOLER DEL CAMPO, A. (1993): La evolución del armamento medieval en el reino castellano-leonés y al-Andalus (siglos XII-XIV), Madrid.

SOLER DEL CAMPO, A. (2001): "El armamento omeya peninsular", El esplendor de los omeyas cordobeses, Barcelona, pp.344-349.

SOLER DEL CAMPO, A (1999): "Armas y armaduras en España”, Las artes decorativas en España, Summa Artis, XLV-II, pp. 101-135, Madrid.

TORRES BALBÁS, L. (1987): "Las artes industriales en le época del califato", España musulmana (711-1031). Instituciones, cultura, sociedad, Historia de España de R. Menéndez Pidal, Tomo V, pp.729-788, Madrid.

THORAVAL, Y. (1996): Diccionario de civilización musulmana, Barcelona.

VALLEJO TRIANO, A. (1987): "El baño próximo al salón de Abd al-Rahman III", Cuadernos de madinat al-Zahra, 1, pp.141-165.

VALLEJO TRIANO, A. y ESCUDERO ARANDA, J. (1999): "Aportaciones para una tipología de la cerámica común califal de Madinat al-Zahra", Arqueología y Territorio Medieval, 6, pp. 133-176, Jaén.

VELMANS, T.; KORAC, V. y SUPUT, M. (1999): Bizancio. El esplendor del arte monumental, Barcelona.

WALSH, J.K (1967): "Supervivencia del árabe s.r.q y g.r.b en el éxico peninsular", Al-Andalus, XXXII, pp. 261-275.

ZAYADINE, F., KEHRBERG, I. y BISHEH, G. (2000): "Ammán, sede del gobernador", Los Omeyas. Los inicios del arte islámico, Madrid.

VV.AA. (1989): Museo de Ávila. Documentación gráfica, Avila.

\section{FUENTES}

AL-IDRĪSĪ (1989): Los caminos de al-Andalus en el siglo XII. Estudio, traducción, edición y anotaciones de Jassim Abid Mizal, CSIC, Madrid.

Recibido: 05/06/2007

Aceptado: 01/07/2007 